NBER WORKING PAPER SERIES

\title{
NEW PERSPECTIVES ON MONETARY POLICY, INFLATION, AND THE BUSINESS CYCLE
}

\author{
Jordi Galí \\ Working Paper 8767 \\ http://www.nber.org/papers/w8767 \\ NATIONAL BUREAU OF ECONOMIC RESEARCH \\ 1050 Massachusetts Avenue \\ Cambridge, MA 02138 \\ February 2002
}

Prepared for an invited session at the World Congress of the Econometric Society, Seattle, August 11-16, 2000. I thank Chris Sims for a useful discussion at the conference. Several sections of the paper draw on previous work of mine with several co-authors, including Richard Clarida, Mark Gertler, David LópezSalido, and Javier Vallés. Financial support from the National Science Foundation, the C.V. Starr Center for Applied Economics, and CREI is gratefully acknowledged. The views expressed herein are those of the author and not necessarily those of the National Bureau of Economic Research.

(C) 2002 by Jordi Galí. All rights reserved. Short sections of text, not to exceed two paragraphs, may be quoted without explicit permission provided that full credit, including (C) notice, is given to the source. 
New Perspectives on Monetary Policy, Inflation, and the Business Cycle

Jordi Galí

NBER Working Paper No. 8767

February 2002

JEL No. E42, E52

\begin{abstract}
The present paper provides an overview of recent developments in the analysis of monetary policy in the presence of nominal rigidities. The paper emphasizes the existence of several dimensions in which the recent literature provides a new perspective on the linkages among monetary policy, inflation, and the business cycle. It is argued that the adoption of an explicitly optimizing, general equilibrium framework has not been superfluous; on the contrary, it has yielded many insights which, by their nature, could hardly have been obtained with earlier non-optimizing models.
\end{abstract}

Jordi Galí

CREI

Ramon Trias Fargas 25

08005 Barcelona

Spain

and NBER

jordi.gali@econ.upf.es

www.econ.upf.es/ gali 


\section{Introduction}

The field of macroeconomics has witnessed in recent years the development of a new generation of small-scale monetary business cycle models, generally referred to as New Keynesian (NK) models or New Neoclassical Synthesis models. The new models integrate Keynesian elements (imperfect competition, and nominal rigidities) into a dynamic general equilibrium framework that until recently was largely associated with the Real Business Cycle (RBC) paradigm. They can be used (and are being used) to analyze the connection between money, inflation, and the business cycle, and to assess the desirability of alternative monetary policies.

In contrast with earlier models in the Keynesian tradition, the new paradigm has adopted a dynamic general equilibrium modelling approach. Thus, equilibrium conditions for aggregate variables are derived from optimal individual behavior on the part of consumers and firms, and are consistent with the simultaneous clearing of all markets. From that viewpoint, the new models have much stronger theoretical foundations than traditional Keynesian models.

In addition, the emphasis given to nominal rigidities as a source of monetary non neutralities also provides a clear differentiation between NK models and classical monetary frameworks. ${ }^{1}$ In the latter, the key mechanism through which money may have some real effects is the so-called inflation tax. But those effects are generally acknowledged to be quantitatively small and not to capture the main sources of monetary non-neutralities at work in actual economies. ${ }^{2}$

The purpose of the present paper is twofold. First, it tries to provide an overview of some of the recent developments in the literature on monetary policy in the presence of nominal rigidities. Given the voluminous literature generated by researchers working in this area, and the usual space constraints, that overview will necessarily be partial. ${ }^{3}$ Second, the paper seeks to emphasize the existence of several dimensions in which the recent literature provides a new perspective on the linkages among monetary policy, inflation, and the business cycle. I would like to argue that the adoption of an explicitly optimizing, general equilibrium framework has not been superfluous; on the contrary, the recent literature has yielded many genuinely new insights which, by their nature, could hardly have been obtained with, say, a textbook IS-LM model.

\footnotetext{
${ }^{1}$ By classical I mean monetary models with perfect competition and flexible prices, and no other frictions (other than those associated with the existence of money).

${ }^{2}$ See, e.g., Cooley and Hansen (1989) for an analysis of a classical monetary model. Several authors have also emphasized the existence of frictions in financial markets as a potential source of nontrivial (and more realistic) monetary non neutralities. See, e.g., Christiano, Eichenbaum and Evans $(1996,1999)$.

${ }^{3}$ It is also likely to somewhat biased in that it attaches a disproportionate weight to issues or areas in which I happen to have done some research myself. Alternative surveys of some of those developments, with a somewhat different focus, can be found in Goodfriend and King (1997) and Clarida, Galí, and Gertler (1999). The present paper does not discuss any of the open economy extensions of NK models, and the issues that openness brings about; the interested reader will find in Lane (2000) a useful survey of developments in that front.
} 
Hence, and contrary to what some macroeconomists may believe, it is not all déja vu and we are not back to where we stood before Kydland and Prescott (1982).

For concreteness, let me summarize next some of the findings, ideas, or features of the new models which one may view as novel, relative to the traditional Keynesian literature. Needless to say the list is not meant to be exhaustive; instead it focuses on some of the issues that are discussed in more detail in the remainder of the paper.

- The NK models bring a new perspective on the nature of inflation dynamics. First, they emphasize the forward looking nature of inflation. As argued below, that property must be inherent to any model where prices are set by firms facing constraints on the frequency with which they can adjust the price of the goods they produce. Firms re-setting their prices today recognize that the prices they choose are likely to remain effective for more than one period. Such firms will find it optimal, when making their current pricing decisions, to take into account their expectations regarding future cost and demand conditions. Since changes in the aggregate price level are (by definition) a consequence of current pricing decisions, it follows that inflation must have an important forward looking component. That property appears clearly reflected in the so called New Phillips curve. As discussed below, it also appears to be a feature of the data. Second, NK models also stress the important role played by variations in markups (or, equivalently, in real marginal costs) as a source of changes in aggregate inflation. The latter can thus be interpreted as the consequence of firms' periodic attempts to correct the misalignment between actual and desired markups.

- The concept of output gap plays a central role in the new optimizing sticky price models, both as a force underlying fluctuations in inflation (through its influence on marginal costs), as well as a policy target. But the notion of output gap found in the recent literature bears little resemblance with the ad-hoc, largely atheoretical output gap measures used in traditional empirical analyses of inflation and monetary policy. In the new paradigm the output gap has a precise meaning: it is the deviation of output from its equilibrium level in the absence of nominal rigidities. Under some assumptions on technology and preferences it is possible to construct a measure of the output gap. As shown below, the resulting measure for the postwar U.S. shows little resemblance with traditional output gap measures.

- In the NK model, the transmission of monetary policy shocks to real variables works through a conventional interest rate channel. Yet, such transmission mechanism does not necessarily involve a liquidity effect, in contrast with the textbook IS-LM model.

- In addition to being a source of monetary nonneutralities, the presence of sticky prices may also have strong implications for the economy's response to non- 
monetary shocks. In particular, recent research has shown that unless monetary policy is sufficiently accommodating, employment is likely to drop in the short run in response to a favorable technology shock. That result is at odds with the predictions of standard RBC models, and contrasts sharply with the mechanisms underlying fluctuations emphasized in the $\mathrm{RBC}$ literature. Most interestingly, the prediction of a negative short run comovement between technology and employment appears to be supported by some recent estimates of the effects of identified technology shocks.

- The adoption of a general equilibrium framework by the recent sticky price literature permits an explicit utility-based welfare analysis of the consequences of alternative monetary policies, and can thus be used as the basis for the design of an optimal (or, at least, desirable) monetary policy. Hence, in the baseline sticky price model developed below the optimal policy stabilizes the price level and the output gap completely. Such a goal is fully attainable, since the central bank does not face a tradeoff between output gap and inflation stabilization. Interestingly, the optimality of a zero inflation arises independently from any desire to reduce the distortion associated with the so called inflation tax; instead, it is exclusively motivated by the policymaker's attempt to offset the distortions associated with staggered price setting, in order to replicate the flexible price equilibrium allocation.

- While the optimal monetary policy requires that the central bank respond systematically to the underlying disturbances in a specific way, a simple policy rule that has the central bank adjust (sufficiently) the interest rate in response to variations in inflation and/or the output gap generally provides a good approximation to the optimal rule (with the implied welfare losses being small). This is generally not the case for other well known simple rules, like a constant money growth or an interest rate peg.

- An interesting new insight found in the recent literature relates to the issue of rules vs. discretion, and the role of credibility in monetary policy. The main result can be summarized as follows: in the presence of a tradeoff between output and inflation, society will generally gain from having a central bank that can (credibly) commit to a state-contingent plan. Most interestingly, such gains from commitment arise even in the absence of a classic inflation bias, i.e. even if the central bank has no desire to push output above its natural level. That result overturns an implication of the classic Barro-Gordon analysis, where the gains from commitment arise only if the central bank sets a target for output that does not correspond to its natural level.

- The coexistence of staggered wage setting with staggered price setting has important implications for monetary policy. In particular, the variations in wage markups caused by not-fully-flexible wages generate a tradeoff between output 
gap and inflation stabilization that is absent from the basic sticky price model. Furthermore, recent research has shown that in such an environment a central bank will generally be unable to eliminate completely the distortions caused by nominal rigidities. The optimal policy will seek to strike a balance between stabilization of three variables: the output gap, price inflation and wage inflation.

The remainder of the paper is organized as follows. Section 2 lays out a baseline sticky price model and derives the corresponding equilibrium conditions. Section 3 focuses on one of the building blocks of that model-the New Phillips Curve-, and discusses some of its implications and empirical relevance. Section 4 uses the baseline model to analyze the effects and transmission of monetary and technology shocks in the presence of sticky prices. Section 5 turns its attention to the endogenous component of monetary policy: it derives the optimal policy rule and assesses the implications of deviating from it by following a simple rule instead. It also shows how the form of the optimal policy is altered by the presence of an inflation/output tradeoff, and discusses the gains from commitment that arise in that context. Section 6 brings sticky wages into the picture and analyzes its consequences for the effects of monetary policy and its optimal design.

\section{Money and Sticky Prices: A Baseline Model}

In this section I lay out a simple model that I take as representative of the new generation of dynamic sticky price models. It is a version of the Calvo (1983) model with staggered price setting. ${ }^{4}$ For simplicity, and in order to focus on the essential aspects of the model, I will work with a simplified version which abstracts from capital accumulation and the external sector. Next I describe briefly the main assumptions, and derive the key equilibrium conditions. ${ }^{5}$

\subsection{Households}

The representative consumer is infinitely-lived and seeks to maximize

$$
E_{0} \sum_{t=0}^{\infty} \beta^{t}\left(\frac{C_{t}^{1-\sigma}}{1-\sigma}-\frac{N_{t}^{1+\varphi}}{1+\varphi}\right)
$$

\footnotetext{
${ }^{4}$ Alternative approaches to modelling price rigidities have been used in the literature. Those include (a) models with staggered price setting à la Taylor (with a certain time between price adjustments), as exemplified by the work of Chari, Kehoe, and McGrattan (1998), and (b) models with convex costs of price adjustment (but no staggering), as in Hairault and Portier (1993) and Rotemberg (1996).

${ }^{5}$ See, e.g., King and Wolman (1996), Yun (1996) and Woodford (1996) for a detailed derivation of the model's equilibrium conditions.
} 
subject to a (standard) sequence of budget constraints and a solvency condition. $N_{t}$ denotes hours of work. $C_{t}$ is a CES aggregator of the quantities of the different goods consumed:

$$
C_{t}=\left(\int_{0}^{1} C_{t}(i)^{\frac{\varepsilon-1}{\varepsilon}} d i\right)^{\frac{\varepsilon}{\varepsilon-1}}
$$

Let $P_{t}=\left(\int_{0}^{1} P_{t}(i)^{1-\varepsilon} d i\right)^{\frac{1}{1-\varepsilon}}$ represent the aggregate price index, where $P_{t}(i)$ denotes the price of good $i \in[0,1]$. The solution to the consumer's problem can be summarized by means of three optimality conditions (two static and one intertemporal), which I represent in log-linearized form (henceforth, lower case letters denote the logarithm of the original variables).

First, the optimal allocation of a given amount of expenditures among the different goods generated by the set of demand schedules implies:

$$
c_{t}(i)=-\varepsilon\left(p_{t}(i)-p_{t}\right)+c_{t}
$$

Second, and under the assumption of a perfectly competitive labor market, the supply of hours must satisfy:

$$
w_{t}-p_{t}=\sigma c_{t}+\varphi n_{t}
$$

where $w$ is the $(\log )$ nominal wage.

Finally, the intertemporal optimality condition is given by the Euler equation:

$$
c_{t}=-\frac{1}{\sigma}\left(r_{t}-E_{t}\left\{\pi_{t+1}\right\}-\rho\right)+E_{t}\left\{c_{t+1}\right\}
$$

where $r_{t}$ is the yield on a nominally riskless one period bond (the nominal interest rate, for short), $\pi_{t+1}$ is the rate of inflation between $t$ and $t+1$, and $\rho=-\log \beta$ represents the time discount rate (as well as the steady state real interest rate, given the absence of secular growth).

Let me also postulate, without deriving it, a standard money demand equation:

$$
m_{t}-p_{t}=y_{t}-\eta r_{t}
$$

which will be used in some of the exercises described below. Notice that a unit income elasticity of money demand is assumed, which is in line with much of the existing empirical evidence.

\section{$2.2 \quad$ Firms}

I assume a continuum of firms, each producing a differentiated good with a technology

$$
Y_{t}(i)=A_{t} N_{t}(i)
$$


where $(\log )$ productivity $a_{t}=\log \left(A_{t}\right)$ follows an exogenous, difference-stationary stochastic process represented by:

$$
\Delta a_{t}=\rho_{a} \Delta a_{t-1}+\varepsilon_{t}^{a}
$$

where $\left\{\varepsilon_{t}^{a}\right\}$ is white noise and $\rho_{a} \in[0,1)$.

I assume that employment is subsidized at a constant subsidy rate $\nu$. Hence, all firms face a common real marginal cost, which in equilibrium is given by

$$
m c_{t}=w_{t}-p_{t}-a_{t}-\nu
$$

Total demand for each good is given by:

$$
Y_{t}(i)=C_{t}(i)+G_{t}(i)
$$

where $G_{t}$ denotes government purchases. For simplicity, I assume that the government consumes a fraction $\tau_{t}$ of the output of each good. Hence, and letting $g_{t}=-\log \left(1-\tau_{t}\right)$, we can rewrite the demand for good $i$ in $\log$ form as follows: ${ }^{6}$

$$
y_{t}(i)=c_{t}(i)+g_{t}
$$

Let $Y_{t}=\left(\int_{0}^{1} Y_{t}(i)^{\frac{\varepsilon-1}{\varepsilon}} d i\right)^{\frac{\varepsilon}{\varepsilon-1}}$ denote aggregate output. The clearing of all goods markets implies

$$
y_{t}=c_{t}+g_{t}
$$

where $y_{t}=\log Y_{t}$. In what follows I assume that a simple $\operatorname{AR}(1)$ process for the demand shock $g_{t}$,

$$
g_{t}=\rho_{g} g_{t-1}+\varepsilon_{t}^{g}
$$

where $\left\{\varepsilon_{t}^{g}\right\}$ is white noise (and orthogonal to $\varepsilon_{t}^{a}$ ) and $\rho_{g} \in[0,1$ ).

Euler equation (4), combined with the market clearing, yields the equilibrium condition

$$
y_{t}=-\frac{1}{\sigma}\left(r_{t}-E_{t}\left\{\pi_{t+1}\right\}-\rho\right)+E_{t}\left\{y_{t+1}\right\}+\left(1-\rho_{g}\right) g_{t}
$$

In addition, and using the fact that $n_{t}=\log \int_{0}^{1} N_{t}(i) d i$, one can derive the following mapping between labor input and output aggregates: ${ }^{7}$

$$
n_{t}=y_{t}-a_{t}
$$

\footnotetext{
${ }^{6}$ One can also interpret $g_{t}$ as a shock to preferences or, more broadly, as an exogenous component of aggregate demand.

${ }^{7}$ For nondegenerate distributions of prices across firms the previous equation holds only up to a first-order approximation. More generally, we have $n_{t}=y_{t}-a_{t}+\xi_{t}$, where $\xi_{t} \equiv \log \int_{0}^{1}\left(\frac{P_{t}(i)}{P_{t}}\right)^{-\varepsilon} d i$ can be interpreted as an indicator of relative price distortions. See Yun (1996) and King and Wolman (1996) for a detailed discussion.
} 
Finally, combining (3), (6), (7), and (9), we obtain an expression for the equilibrium real marginal cost in terms of aggregate output and productivity:

$$
m c_{t}=(\sigma+\varphi) y_{t}-(1+\varphi) a_{t}-\sigma g_{t}-\nu
$$

Notice that in deriving all the equilibrium relationships above I have not made use of any condition specifying how firms set their prices. Next I describe two alternative models of price setting, which differ in the existence or not of restrictions on the frequency with which firms may adjust prices.

\subsection{Flexible Price Equilibrium}

Suppose that all firms adjust prices optimally each period, taking the path of aggregate variables as given. The assumption of an isoelastic demand implies that they will choose a markup (defined as the ratio of price to marginal cost) given by $\frac{\varepsilon}{\varepsilon-1}$. That markup will be common across firms, and constant over time. Hence, it follows that the real marginal cost (i.e., the inverse of the markup) will also be constant, and given by

$$
m c_{t}=-\mu
$$

for all $t$, where $\mu=\log \left(\frac{\varepsilon}{\varepsilon-1}\right){ }^{8} \quad$ Furthermore, given identical prices and demand conditions the same quantities of all goods will be produced and consumed.

In that case the equilibrium processes for output, consumption, hours, and the expected real rate are given by:

$$
\begin{gathered}
\bar{y}_{t}=\gamma+\psi_{a} a_{t}+\psi_{g} g_{t} \\
\bar{c}_{t}=\gamma+\psi_{a} a_{t}-\left(1-\psi_{g}\right) g_{t} \\
\bar{n}_{t}=\gamma+\left(\psi_{a}-1\right) a_{t}+\psi_{g} g_{t} \\
\overline{r r}_{t}=\rho+\sigma \psi_{a} \rho_{a} \Delta a_{t}+\sigma\left(1-\psi_{g}\right)\left(1-\rho_{g}\right) g_{t}
\end{gathered}
$$

where $\psi_{a}=\frac{1+\varphi}{\sigma+\varphi}, \psi_{g}=\frac{\sigma}{\sigma+\varphi}$, and $\gamma=\frac{\nu-\mu}{\sigma+\varphi}$. Henceforth, I refer to the above equilibrium values as the natural levels of the corresponding variable.

Notice that, in the absence of nominal rigidities, the equilibrium behavior of the above variables is independent of monetary policy. Furthermore, if $\gamma=0$, the equilibrium allocation under flexible prices coincides with the efficient allocation, i.e., the one that would obtain under flexible prices, perfect competition, and no distortionary taxation of employment (i.e., $\nu=\mu=0$ ). Attaining that efficient allocation requires setting $\nu=\mu$, i.e. using an employment subsidy that exactly offsets the distortion associated with monopolistic competition. As further discussed below, that assumption will generally be maintained in what follows. ${ }^{9}$

\footnotetext{
${ }^{8}$ Henceforth, an upper bar is used to denote the equilibrium value of a variable under flexible prices.

${ }^{9}$ A similar assumption can be found in Woodford (1999), Obstfeld and Rogoff (1999), and Gali and Monacelli (1999).
} 


\subsection{Staggered Price Setting}

The exact form of the equation describing aggregate inflation dynamics depends on the way sticky prices are modeled. Let me follow Calvo (1983), and assume that each firm resets its price in any given period only with probability $1-\theta$, independently of other firms and of the time elapsed since the last adjustment. Thus, a measure $1-\theta$ of producers reset their prices each period, while a fraction $\theta$ keep their prices unchanged. Let $p_{t}^{*}$ denote the log of the price set by firms adjusting prices in period $t .{ }^{10}$ The evolution of the price level over time can be approximated by the log-linear difference equation:

$$
p_{t}=\theta p_{t-1}+(1-\theta) p_{t}^{*}
$$

One can show that a firm seeking to maximize its value will choose the price of its good according to the (approximate) log-linear rule

$$
p_{t}^{*}=\mu+(1-\beta \theta) \sum_{k=0}^{\infty}(\beta \theta)^{k} E_{t}\left\{m c_{t+k}^{n}\right\}
$$

i.e., prices are set as a markup over a weighted average of current and expected future nominal marginal costs $\left\{m c_{t+k}^{n}\right\}$.

In order to get some intuition for the form of that rule, let $\mu_{t, t+k}=p_{t}^{*}-m c_{t+k}^{n}$ denote the markup in period $t+k$ of a firm that last set its price in period $t$. We can rewrite (16) as $\mu=(1-\beta \theta) \sum_{k=0}^{\infty}(\beta \theta)^{k} E_{t}\left\{\mu_{t, t+k}\right\}$ which yields a simple interpretation of the pricing rule: firms set prices at a level such that a (suitable) weighted average of anticipated future markups matches the optimal frictionless markup $\mu$.

If firms do not adjust prices optimally each period, real marginal costs will no longer be constant. On the other hand, in a perfect foresight steady state with zero inflation, all firms will be charging their desired markup. Hence, the steady state marginal cost, $m c$, will be equal to its flexible price counterpart (i.e., $-\mu$ ). Let $\widehat{m c}_{t}=m c_{t}-m c$ denote the percent deviation of marginal cost from its steady state level. We can then combine (15) and (16), and, after some algebra, obtain a simple stochastic difference equation describing the dynamics of inflation, with marginal costs as a driving force:

$$
\pi_{t}=\beta E_{t}\left\{\pi_{t+1}\right\}+\lambda \widehat{m c}_{t}
$$

where $\lambda=\theta^{-1}(1-\theta)(1-\beta \theta)$.

Furthermore, firms' inability to adjust prices optimally every period will generally imply the existence of a wedge between output and its natural level. Let me denote that wedge by $x_{t}=y_{t}-\bar{y}_{t}$, and refer to it as the output gap. It follows from (10) that the latter will be related to marginal cost according to

$$
\widehat{m c}_{t}=(\sigma+\varphi) x_{t} .
$$

\footnotetext{
${ }^{10}$ Notice that they will all be setting the same price, since they face an identical problem.
} 
Combining (17) and (18) yields the familiar New Phillips Curve:

$$
\pi_{t}=\beta E_{t}\left\{\pi_{t+1}\right\}+\kappa x_{t}
$$

where $\kappa=\lambda(\sigma+\varphi)$.

It will turn out to be convenient for the subsequent analysis to rewrite equilibrium condition (8) in terms of the output gap and the natural rate of interest:

$$
x_{t}=-\frac{1}{\sigma}\left(r_{t}-E_{t}\left\{\pi_{t+1}\right\}-\overline{r r}_{t}\right)+E_{t}\left\{x_{t+1}\right\}
$$

Equations (19) and (20), together with a specification of monetary policy (i.e., of how the interest rate evolves over time), and of the exogenous processes $\left\{a_{t}\right\}$ and $\left\{g_{t}\right\}$ (which in turn determine the natural rate of interest), fully describe the equilibrium dynamics of the baseline model economy.

Having laid out the equations of the baseline sticky price model, I now turn to a discussion of some of its implications for monetary policy, inflation and the business cycle.

\section{The Nature of Inflation Dynamics}

The nature of inflation dynamics is arguably the most distinctive feature of the New Keynesian paradigm. Yet, an important similarity with traditional Keynesian models remains on this front: as illustrated by (19), the evolution of inflation in the NK model is determined by some measure of the level of economic activity or, more precisely, of its deviation from some baseline level. Thus, and in contrast with classical monetary models, a change in monetary conditions (e.g., an increase in the money supply) has no direct effect on prices. Its eventual impact is only indirect, working through whatever changes in the level of economic activity it may induce. That common feature notwithstanding, there exist two fundamental differences between (19) and a traditional Phillips curve. First, in the new paradigm inflation is determined in a forward looking manner. Second, the measure of economic activity that is the driving force behind inflation fluctuations is precisely pinned down by the theory, and may not be well approximated by conventional output gap measures. Next we discuss those two features in more detail, together with their empirical implications and the related evidence.

\subsection{The Forward Looking Nature of Inflation}

The traditional Phillips Curve relates inflation to some cyclical indicator as well as its own lagged values. A simple and common specification takes the form:

$$
\pi_{t}=\pi_{t-1}+\delta \widehat{y}_{t}+\varepsilon_{t}
$$


where $\widehat{y}_{t}$ the log deviation of GDP from some baseline trend (or from some measure of potential GDP) and $\varepsilon_{t}$ is a random disturbance. Sometimes additional lags of inflation or detrended GDP are added. Alternative cyclical indicators may also be used (e.g., the unemployment rate). Let me emphasize two properties, which will generally hold independently of the details. First, past inflation matters for the determination of current inflation. Second, current inflation is positively correlated with past output; in other words, output leads inflation.

The previous properties stand in contrast with those characterizing the New Phillips Curve (NPC). Taking equation (19) as a starting point, and iterating forward yields:

$$
\pi_{t}=\kappa \sum_{k=0}^{\infty} \beta^{k} E_{t}\left\{x_{t+k}\right\}
$$

It is clear from the expression above that past inflation is not, in itself, a relevant factor in determining current inflation. Furthermore, inflation is positively correlated with future output, given $\left\{\bar{y}_{t+k}\right\}$. In other words, inflation leads output, not the other way around. Thus, we see that under the new paradigm, inflation is a forward looking phenomenon. The intuition behind that property is clear: in a world with staggered price setting, inflation-positive or negative-arises as a consequence of price decisions by firms currently setting their prices; as made clear by (16), those decisions are influenced by current and anticipated marginal costs, which are in principle unrelated to past inflation.

Interestingly, many critical assessments of the New Keynesian paradigm have focused on the forward looking nature of the inflation dynamics embedded in it. Thus, a number of authors have argued that, while the NPC may be theoretically more appealing, it cannot account for many features of the data that motivated the traditional Phillips curve specification. In particular, they point out that the pattern of dynamic cross-correlation between inflation and detrended output observed in the data suggests that output leads inflation, not the other way around. ${ }^{11}$ In other words, the data appears to be more consistent with a traditional, backward-looking Phillips curve than with the new. That evidence seems reinforced by many of the estimates of hybrid Phillips curves of the form

$$
\pi_{t}=\gamma_{b} \pi_{t-1}+\gamma_{f} E_{t}\left\{\pi_{t+1}\right\}+\delta\left(y_{t}-\bar{y}_{t}\right)
$$

found in the literature, and which generally point to a significant (if not completely dominant) influence of lagged inflation as a determinant of current inflation. ${ }^{12}$

That critical assessment of the NPC has been revisited recently by Sbordone (1999), Gertler and Galí (1999; henceforth, GG), and Gertler, Galí and López-Salido (2000; henceforth, GGL). Those authors argue that some of the existing evidence against the relevance of the NPC may be distorted by the use of detrended GDP (or

\footnotetext{
${ }^{11}$ This point has been stressed by Fuhrer and Moore (1995), among others.

${ }^{12}$ See, Chadha, Masson, and Meredith (1992) and Fuhrer (1997), among others.
} 
similar) as a proxy for the output gap. As discussed in the next subsection, that proxy is likely to be very poor and, thus, a source of potentially misleading results. Furthermore, even if detrended GDP was highly correlated with the true output gap, the conditions under which the latter is proportional to the (current) marginal cost may not be satisfied; that would render (19) invalid and lead to a misspecification of the NPC formulation used in empirical work.

As a way to overcome both problems the abovementioned researchers have gone back one step and estimated (17) instead, thus taking real marginal cost as the (immediate) driving force underlying changes in inflation. That formulation of the inflation equation relies on weaker assumptions, since condition (18) is no longer required to hold. On the other hand it embeds two essential ingredients of inflation dynamics under the new paradigm: (a) the forward looking nature of price-setting decisions and (b) their lack of synchronization (staggering).

Most importantly, they note that a theory-consistent, observable measure of average real marginal costs can be derived under certain assumptions on technology, and independently of price-setting considerations. ${ }^{13}$ For the sake of concreteness, suppose that (a) labor productivity is exogenous, (b) firms take wages as given, and (c) there are no costs of labor adjustment. Then it is easy to show that real marginal costs will be proportional to the labor income share; it follows that $\widehat{m c}_{t}=\widehat{s}_{t}$, where $\widehat{s}_{t}$ denotes the percent deviation of the labor income share from its (constant) mean.

Using U.S. data on inflation and the labor income share, GG have estimated (17), as well as structural parameters $\beta$ and $\theta$ using an instrumental variables estimator. That evidence has recently been extended by GGL to Euro area data. An exercise in a similar spirit has been carried out by Sbordone, using an alternative approach to estimation based on a simple goodness-of-fit criterion that seeks to minimize the model's forecast error variance, given a path for expected marginal costs.

The findings that emerge in that recent empirical work are quite encouraging for the NPC: when the latter is estimated in a way consistent with the underlying theory it appears to fit the data much better than it had been concluded by the earlier literature. Thus, all the parameter estimates have the predicted sign and show plausible values. In particular, estimates of parameter $\theta$ imply an average price duration of about one year, which appears to be roughly consistent with the survey evidence. $^{14}$

The GG and GGL papers also provide an extension of the baseline theory underlying the NPC to allow for a constant fraction of firms that set prices according to a simple, backward-looking rule of thumb. The remaining firms set prices in a forward-looking way, as in the baseline sticky price model. The reduced form inflation equation that results from the aggregation of pricing decisions by both types of firms takes a hybrid form similar to (23), with a measure of marginal cost replacing

\footnotetext{
${ }^{13}$ See Rotemberg and Woodford (1999) for a detailed discussion of alternative measures of marginals costs.

${ }^{14}$ See Taylor (1999) for an overview of that evidence.
} 
the output gap, and with coefficients $\gamma_{b}$ and $\gamma_{f}$ being a function of all structural parameters (now including the fraction of firms that are backward looking). The findings there are also quite encouraging for the baseline NPC: while backward looking behavior is often statistically significant, it appears to have limited quantitative importance. In other words, while the baseline pure forward looking model is rejected on statistical grounds, it is still likely to be a reasonable first approximation to the inflation dynamics of both Europe and the U.S. ${ }^{15}$

\subsection{The Nature of the Output Gap}

According to the NPC paradigm, inflation fluctuations are associated with variations in the output gap, i.e., in the deviation of output from its level under flexible prices. ${ }^{16}$ The output gap and its volatility also play an important role in welfare evaluations: as shown in Rotemberg and Woodford (1997), the variance of the output gap is one of the key terms of a second order approximation to the equilibrium utility of the representative consumer, in the context of a model similar to the one sketched above.

The concept of output gap associated with the NK model is very different from the one implicit in most empirical applications. In the latter, the concept of output gap used would be better characterized as a measure of detrended output, i.e., deviations of log GDP from a smooth trend. That trend is computed using one of a number of available procedures, but the main properties of the resulting series do not seem to hinge critically on the exact procedure used. This is illustrated in Figure 1, which plots three "output gap" series for the U.S. economy commonly used in empirical work. Those gap measures correspond to three alternative estimates of the trend: (a) a fitted quadratic function of time, (b) a Hodrick-Prescott filtered series, (c) the Congressional Budget Office's estimate of potential output. The fact that the implied trend is a very smooth series has two implications. First, the bulk of the fluctuations in output at business cycle frequencies are attributed to fluctuations in the output gap. Second, the correlation among the three output gap measures is very high.

But, as argued in GG and Sbordone, the use of detrended GDP as a proxy for the output gap does not seem to have any theoretical justification. In effect, that approach implicitly assumes that the natural level of output $\left\{\bar{y}_{t}\right\}$ can be represented as a smooth function of time. Yet, the underlying theory implies that any shock (other than monetary shocks) may be a source of fluctuations in that natural level of output; as a result, the latter may be quite volatile. ${ }^{17}$ In fact, one of the tenets of the RBC school was that the bulk of the business cycle in industrial countries could be

\footnotetext{
${ }^{15}$ Interestingly, as shown in GGL, the backward looking component appears to be even less important in Europe than in the US.

${ }^{16}$ As should be clear from the derivation of (19) that relationship is not a primitive one. It arises from the proportionality between the output gap and markups (or real marginal costs) which holds under some standard, though by no means general, assumptions.

${ }^{17}$ See, e.g., Rotemberg and Woodford (1999) for an illustration of this point in the context of a calibrated version of a sticky price model..
} 
interpreted as the equilibrium response of a frictionless economy to technology and other real shocks; in other words, to fluctuations in the natural level of output!.

Under the assumptions made in section 2, and as shown in equation (18), the true output gap is proportional to deviations of real marginal cost from steady state. Hence, a measure of real marginal cost can be used to approximate (up to a scalar factor) the true, or model-based, output gap. Figure 2 displays a time series for the U.S. output gap, defined as $x_{t}=0.5 \widehat{s}_{t}$. Notice that this is consistent, e.g., with parameter settings $\sigma=1$ and $\varphi=1$; those values arguably fall within a reasonable range. In addition, Figure 2 also shows the deviation of log GDP from a fitted quadratic trend, a popular proxy for the output gap in empirical applications. Let me not emphasize here the apparent differences in volatility between the two series, since the model pins down the output gap only up to a scale factor (determined by the choice of settings for $\sigma$ and $\varphi$ ). Instead I want to focus on their comovement: if detrended GDP was a good proxy for the output gap, we should observe a strong positive comovement between the two series. But a look at Figure 3 makes it clear that no obvious relationship exists; in fact, the contemporaneous correlation between them turns out to be slightly negative. As argued in Galí and Gertler (1999), the previous finding calls into question the validity of empirical tests of the New Phillips curve that rely on detrended GDP as a proxy for the output gap, including informal assessments based on the patterns of cross-correlations between that variable and inflation.

\section{The Effects and Transmission of Shocks}

Having laid out the baseline NK model and discussed some of its most distinctive elements, I turn to the examination of some of its predictions regarding the effects of some aggregate shocks on the economy.

Much of the quantitative analysis that follows relies on a baseline calibration of the model, though a number of variations from it are also considered. In the baseline calibration, I assume a log utility for consumption, which corresponds to $\sigma=1$. This is a standard assumption, and one that would render the model consistent with a balanced growth path if secular technical progress was introduced. I also set $\varphi=1$, which implies a unit wage elasticity of labor supply. The baseline value for the semielasticity of money demand with respect to the (quarterly) interest rate, $\eta$, is set to unity. This is roughly consistent with an interest elasticity of 0.05 found in empirical estimates and used in related work. ${ }^{18}$ The baseline choice for $\theta$ is 0.75 . Under the Calvo formalism that value implies an average price duration of one year. This appears to be in line with econometric estimates of $\theta$, as well as survey evidence. ${ }^{19}$ The elasticity of substitution $\varepsilon$ is set to 11 , a value is consistent with a 10 percent

\footnotetext{
${ }^{18}$ See, e.g., Chari, Kehoe, and McGrattan (1997)

${ }^{19}$ Taylor (1999) summarizes the existing survey evidence.
} 
markup in the steady state. Finally, I set $\beta=0.99$, which implies an average annual real return of about 4 percent.

\subsection{Monetary Policy Shocks}

As is well known, the presence of nominal rigidities is a potential source of nontrivial real effects of monetary policy shocks. This is also the case for the baseline NK model, where firms do not always adjust the price of their good when they receive new information about costs or demand conditions.

What are the real effects of monetary policy shocks in the above framework? How are they transmitted? In order to focus attention on these issues we abstract momentarily from non-monetary shocks by assuming $a_{t}=g_{t}=0$, for all $t$. Without loss of generality I also set $\bar{y}_{t}=0$, all $t$.

Solving (8) forward one obtains:

$$
y_{t}=-\frac{1}{\sigma} \sum_{k=0}^{\infty} E_{t}\left\{r_{t+k}-\pi_{t+k+1}-\rho\right\}
$$

We see that in the NK model exogenous interventions by the monetary authority will have an effect on output only to the extent they influence current or future expected short term real interest rates or, equivalently-under the expectations hypothesis of the term structure-only if they affect the current long term real rate.

To understand how the transmission works, I specify monetary policy by assuming an exogenous path for the growth rate of the money supply, given by the stationary process:

$$
\Delta m_{t}=\rho_{m} \Delta m_{t-1}+\varepsilon_{t}^{m}
$$

where $\rho_{m} \in[0,1)$. Under that assumption, the equilibrium dynamics of the baseline NK model are described by the stationary system:

$$
\left[\begin{array}{ccc}
1+\frac{1}{\sigma \eta} & 0 & 0 \\
-\kappa & 1 & 0 \\
0 & -1 & 1
\end{array}\right]\left[\begin{array}{c}
y_{t} \\
\pi_{t} \\
m_{t-1}-p_{t-1}
\end{array}\right]=\left[\begin{array}{ccc}
1 & \frac{1}{\sigma} & \frac{1}{\sigma \eta} \\
0 & \beta & 0 \\
0 & 0 & 1
\end{array}\right]\left[\begin{array}{c}
E_{t}\left\{y_{t+1}\right\} \\
E_{t}\left\{\pi_{t+1}\right\} \\
m_{t}-p_{t}
\end{array}\right]+\left[\begin{array}{c}
0 \\
0 \\
-1
\end{array}\right] \Delta m_{t}
$$

As a baseline setting for $\rho_{m}$ I choose 0.5 , a value consistent with the estimated autoregressive process for M1 in the United States. The estimated standard deviation of the money shock, denoted by $\sigma_{m}$, is approximately 0.01 . For convenience, I set $\sigma_{m}=1$, which requires that the units of all variables be interpreted as percentage points or percent deviations. ${ }^{20}$

Figure 3 displays the dynamic responses of output, inflation, and both nominal and (ex-ante) real rates to a one-standard deviation money supply shock, under the

\footnotetext{
${ }^{20}$ Cooley and Hansen (1989), Walsh (1998) and Yun (1996) justify the choice of that calibration.
} 
baseline calibration. For ease of interpretation, the rates of inflation and interest rate displayed in the figure have been annualized (the calibration is based on quarterly rates, however).

I would like to highlight two features of the responses shown in Figure 3. First, they suggest that in the simple sticky price model considered here a "typical" monetary shock has strong, and highly persistent, effects on output. Second, under the baseline calibration, a monetary expansion is predicted to raise the nominal rate; in other words, the calibrated model does not predict the existence of a liquidity effect. Next I discuss briefly each of these properties in turn.

\subsubsection{The Effects of Money on Output: Strength and Persistence}

What level of GNP volatility can be accounted for by the basic NK model, when shocks to an exogenous money supply process (calibrated in accordance to postwar U.S. data) are the only source of fluctuations? For our baseline calibration the answer to the previous question is a surprisingly large value: 2.1 percent. That value is significantly above the estimated standard deviation of detrended U.S. GDP in the postwar period. ${ }^{21}$ Interestingly, and despite their focus on the persistence of the shocks, Chari, Kehoe and McGrattan (2000) document a dual result in the context of the Taylor-type model: they calibrate $\sigma_{m}$ in order to match the volatility of output, leading them to set at a value well below the estimated one. ${ }^{22}$

While the previous exercise is useful at pointing out the powerful real effects of changes in the money supply, there are many reasons not to take it too literally. For one, the estimated variance of money supply shocks is likely to overstate the true volatility of the unexpected component of money since, by construction, specification (25) ignores the existence of any endogenous component of variations in the money supply. ${ }^{23}$ That notwithstanding, Figure 3 makes clear that the effects of monetary policy on output are far from negligible: on impact, a one percent increase in the money supply raises output by more than 1 percent, while the implied increase in the price level is of about 2.4 percent (annualized).

In addition to the large output effects of money discussed above, the baseline model also implies that such effects are quite persistent. That property is apparent in the impulse response of output displayed in Figure 3. In particular, the half life of that output response under the baseline calibration is 3.2 quarters. ${ }^{24}$

\footnotetext{
${ }^{21}$ Stock and Watson (1999) report a standard deviation of 1.66 percent for the period 53-96, using a band-pass filter to isolate cyclical fluctuations. Other estimates in the literature are similar.

${ }^{22}$ See also Walsh (1998) and Yun (1996) for a similar result.

${ }^{23}$ The analogy with the calibration of technology changes based on an estimated process for the Solow residual seems appropriate.

${ }^{24}$ The previous result contrasts with the findings of Chari et al. (2000), who stress the difficulty in generating significant effects of money on output beyond the duration of price (which is deterministic in their framework).
} 


\subsubsection{The Presence (or Lack Thereof) of a Liquidity Effect}

As shown in Figure 3, under the baseline calibration of the NK model, a monetary expansion raises the nominal rate. Hence, and in contrast with a textbook model, the calibrated model does not predict the existence of a liquidity effect. Still, that feature does not prevent monetary policy from transmitting its effects through an interest rate channel: as shown in the same figure, the (ex-ante) real rate declines substantially when the monetary expansion is initiated, remaining below its steady state level for a protracted period. As (24) makes clear, it is that persistent decline which induces the observed expansion in aggregate demand and output.

The absence of a liquidity effect is not, however, a robust feature of the NK model. Yet, and as discussed in Christiano, Eichenbaum and Evans (1996), and Andrés, López-Salido, and Vallés (1999), standard specifications of preferences and the money growth process tend to rule out a liquidity effect. In order to understand the factors involved, notice that the interest rate can be written as: ${ }^{25}$

$$
r_{t}=\left(\frac{\sigma-1}{1+\eta}\right) \sum_{k=1}^{\infty}\left(\frac{\eta}{1+\eta}\right)^{k-1} E_{t}\left\{\Delta y_{t+k}\right\}+\left(\frac{\rho_{m}}{1+\eta\left(1-\rho_{m}\right)}\right) \Delta m_{t}
$$

Under the baseline calibration we have $\sigma=1$; in that case, (27) implies that the nominal rate will be proportional to the expected growth rate of money, $\rho_{m} \Delta m_{t}$. To the extent that money growth is positively serially correlated (as it is the case in our baseline calibration), the nominal rate will necessarily increase in response to a monetary expansion.

Under what conditions can the liquidity effect be restored? Notice that, to the extent that a monetary expansion raises output on impact, the term $\sum_{k=1}^{\infty}\left(\frac{\eta}{1+\eta}\right)^{k-1} E_{t}\left\{\Delta y_{t+k}\right\}$ will generally be negative. ${ }^{26}$ Accordingly, the presence of a liquidity effect requires a sufficiently high risk aversion parameter $\sigma$ (for any $\rho_{m}$ ) or, given $\sigma>1$, a sufficiently low money growth autocorrelation $\rho_{m}$. The previous tradeoff is clearly illustrated in Figure 4, which displays the impact effect on the nominal rate of a unit monetary shock, as a function of $\sigma$ and $\rho_{m}$. The bottom graph shows a sample of loci of $\sigma$ and $\rho_{m}$ configurations associated with a given interest rate change. Hence, the zero locus represents the "liquidity effect frontier": any $\left\{\sigma, \rho_{m}\right\}$ combination above and to the left of that locus will be associated with the presence of a liquidity effect. We see that, under the baseline calibration $\left(\rho_{m}=0.5\right)$, a risk aversion parameter of size slightly above 4 is necessary to generate a liquidity effect.

\footnotetext{
${ }^{25}$ In order to derive that expression first-difference (5) and combine the resulting expression with (20); some algebraic manipulation then yields the expression in the text.

${ }^{26}$ Long run neutrality of money implies that $\lim _{k \rightarrow \infty} E_{t}\left\{y_{t+k}\right\}=0$. Hence, the sign of the summatory in (27) will be positive if (a) output's reversion to its initial level is monotonic (as in the impulse response displayed in Figure 5), and/or (b) if $\eta$ is sufficiently large.
} 


\subsection{Technology Shocks}

Proponents of the RBC paradigm have claimed a central role for exogenous variations in technology as a source of observed economic fluctuations. On the other hand, the analysis of models with nominal rigidities has tended to emphasize the role of demand and, in particular, monetary disturbances as the main driving forces behind the business cycle.

Recently, however, a number of papers have brought attention to a surprising aspect of the interaction between sticky prices and technological change. In particular, Galí (1999) and Basu, Fernald, and Kimball (1999; henceforth, BFK) have made the following observation: in a model with imperfect competition and sticky prices, a favorable technology shock is likely to induce a short run decline in employment, so long as the response of the monetary authority falls short of full accommodation. ${ }^{27}$ That prediction is illustrated in Figure 5, where the dynamic responses of inflation, the output gap, output, and employment to a one percent permanent increase in productivity are displayed, using the baseline model developed above under the assumption of a constant money supply. Figure 6 examines the robustness of that prediction to changes in the degree of price rigidities and the risk aversion parameter, by displaying the response of employment on impact for a range of values of those parameters, as well as the corresponding contour plots. Hence we see that while a negative response of employment to a favorable technology shock is not a necessary implication of the model, that prediction appears to hold for a very large subset of the parameter values considered. More specifically, employment is seen to increase in response to a positive technology shock only when a low risk aversion parameter coexists with little nominal rigidities (i.e., the south-west corner of the figure).

The intuition behind that result can be easily grasped by considering the case of an interest-inelastic money demand, so that $y_{t}=m_{t}-p_{t}$ holds in equilibrium. Assume, for the sake of argument, that the money supply remains unchanged in the wake of a technology shock. Notice also that even though all firms will experience a decline in their marginal cost only a fraction of them will adjust their prices downwards in the short run. Accordingly, the aggregate price level will decline, and aggregate demand will rise, less than proportionally to the increase in productivity. That, in turn, induces a decline in aggregate employment. ${ }^{28}$

The previous characterization of the economy's response to a positive technology shock is clearly at odds with some central implications of the standard RBC model. The latter's prediction of a positive short run comovement between productivity, output and employment in response to technology shocks lies at the root of the

\footnotetext{
${ }^{27}$ Not surprisingly, the pattern of response of employment and any other variable will depend on the systematic response of the monetary authority to those shocks, as argued in Dotsey (1999).

${ }^{28} \mathrm{BFK}$ 's model allows for the possibility of a short run decline in output after a positive technology shock. That outcome can be ruled out in the baseline model considered here, under the assumption of a constant money supply and $\sigma=1$. In that case the nominal rate remains unchanged (see eq. (27)), and output has to move in the opposite direction from prices (which go down).
} 
ability of an RBC model to replicate some central features of observed aggregate fluctuations, while relying on exogenous variations in technology as the only (or, at least, the dominant) driving force.

But, how does the actual economy respond to technology shocks? Which of the two competing frameworks does it favor? Galí (1999) and BFK (1999) provide some evidence pertaining to this matter, by estimating the responses of a number of variables to an identified technology shock. While the approach to identification is very different in the two cases, the results that emerge are similar: in response to a positive technology shock, labor productivity rises more than output, while employment shows a persistent decline. Hence, conditional on technology as a driving force, the data point to a negative correlation between employment and productivity, as well as between employment and output. Both observations call into question the empirical relevance of the mechanism through which aggregate variations in technology are transmitted to the economy in the basic RBC model. Perhaps most importantly, and independently of the reference model, they raise serious doubts about the quantitative significance of technology shocks as a source of aggregate fluctuations in industrialized economies.

\section{The Design of Monetary Policy}

The previous section looked at the effects of exogenous changes in the money supply in the context of a calibrated sticky price model. The usefulness of that sort of analysis is twofold. First, it helps us understand the way changes in monetary policy are transmitted to a number of macroeconomic variables in the model of reference. Second, it allows for an empirical evaluation of the underlying model, through a comparison of the estimated responses to an exogenous monetary shock against the model's predictions regarding the effects of a monetary intervention that corresponds to the experiment observed in the data. ${ }^{29}$ Yet, the limitations of such a specification of monetary policy are by now well understood. For one, the common practice of modern central banks does not involve the use of the quantity of money as a policy instrument, and only very seldom as an intermediate target. Furthermore, the assumption of an exogenous random process for the money supply (or any other policy instrument, for that matter), while convenient for certain purposes, can hardly be viewed as a plausible one, since it is equivalent to modeling monetary policy as a process of randomization over the possible values of a policy instrument. This is clearly at odds with even a casual observation of how central banks conduct monetary policy.

Instead, much recent research in monetary economics, both theoretical and empirical, has de-emphasized the analysis of monetary shocks and its effects, and turned instead its focus on the endogenous component of monetary policy. ${ }^{30}$ There are several

\footnotetext{
${ }^{29}$ See Christiano, Eichenbaum and Evans (1998) for a discussion of that methodological approach.

${ }^{30}$ That shift in emphasis may not be unrelated to a common finding in the structural VAR litera-
} 
natural questions that one can ask in that context. What are the goals of monetary policy? How should monetary policy be conducted in order to achieve those goals? In particular, how should the monetary authority respond to different shocks? What are the losses from following simple rules, that depart from the optimal one?

It is beyond the scope of the present paper to attempt to provide a general treatment of such important questions. Instead, I use the baseline sticky price model developed above to illustrate how some of those questions can be addressed with the tools of modern monetary theory. In order to keep things manageable, and to focus on the role of nominal rigidities in the design of monetary policy, most of the analysis maintains the assumption that the presence of such rigidities is the only distortion left for the monetary authority to correct.

\subsection{The Goals of Monetary Policy}

In setting up the problem facing the monetary authority, we adopt the natural assumption that it acts as a benevolent policymaker, i.e., it seeks to maximize the utility of the representative household. That optimization problem is subject to some economy-wide resource constraints, as well as institutional and/or informational constraints that may limit the sort of interventions that the monetary authority can undertake.

In practice, the optimizing policymaker will seek to eliminate (or, at least, to offset as much as possible) any distortions that may exist in the economy. Models of monetary economies with staggered price setting found in the literature would typically have as many as four distortions, briefly described next. ${ }^{31}$

A first distortion results from agents' need or desire to allocate part of their wealth to (non interest bearing) monetary assets, given the transaction services provided by the latter. The existence of a private opportunity cost of holding such monetary balances coexisting with a zero social cost of producing them, generates a transactions/monetary distortion. The elimination of that distortion requires that the nominal interest rate is set to zero (the Friedman rule), in order to equate private and social costs. ${ }^{32}$ The average level of inflation associated with a zero nominal rate is given by minus the steady state equilibrium real rate $(\pi=-\rho$, in the framework above). Hence, policies that seek to implement the Friedman rule will generally

ture: identified exogenous monetary policy disturbances account only for a relatively small portion of the observed fluctuations in output and other macroeconomic variables, including monetary instruments and aggregates. An important component of the latter's variations must hence be attributed to the systematic reaction of the monetary authority to macroeconomic developments, i.e., to the endogenous component of monetary policy. See Sims (1996), and Christiano, Eichenbaum and Evans (1999) for two recent overviews of that literature.

${ }^{31}$ See Khan, King, and Wolman (2000) and Woodford (1999c) for a detailed analysis of the role played by each distortion in the design of monetary policy.

${ }^{32}$ See Correia and Teles (1999) for a modern treatment of the optimality of the Friedman rule in classical monetary models, under a variety of assumptions. 
involve a steady decline in the price level.

A second distortion results from the existence of imperfect competition in the goods market. That feature is reflected in prices that are, on average, above marginal cost. In equilibrium, that property makes the marginal rate of substitution between consumption and labor (the real wage) differ from their corresponding marginal rate of transformation (the marginal product of labor). The existence of such a static or average markup distortion is often invoked to rationalize an objective function for the policymaker which penalizes deviations of the output gap $x_{t}$ from a positive target $x^{*}>0$. The latter corresponds to the efficient level of activity (i.e., the one that would obtain under perfect competition). Thus, and in the absence of an employment subsidy $(v=0)$, the output gap target in the model of section 2 would be given by $x^{*}=\frac{\mu}{\sigma+\varphi}$. The steady state rate of inflation that would be associated with that output gap can be easily derived using (19), and is approximately given by $\pi \simeq \frac{\lambda \mu}{\rho}>0$. Thus, using monetary policy to offset the distortion created by the existence of market power would require a departure from the Friedman rule, and would thus conflict with attempts to reduce the monetary distortion. ${ }^{33}$

Notice that the two distortions just discussed would be operative even in the limiting case of full price flexibility; in other words, they are not related to the presence of nominal rigidities. In the subsequent analysis I choose to ignore the previous distortions, and focus instead on those resulting from the presence of sticky prices and staggered price setting. This is equivalent to taking the welfare gains from holding higher real balances to be small ${ }^{34}$ (relative to the utility derived from consumption of goods and leisure), and to assume that the static market power distortion is exactly offset by means of an employment subsidy of the right size (financed through lump sum taxes). In such a world there would remain at least two additional distortions, both directly related to the presence of sticky prices and the staggered nature of price setting. On the one hand, firms' inability to adjust prices each period in the face of shocks will lead to persistent deviations of markups from their frictionless level (equivalently, it will generate inefficient fluctuations in the output gap). Let me refer to that source of inefficiency as the dynamic markup distortion. In addition, the lack of synchronization in price adjustments will generally imply the coexistence of different prices (and, hence, different quantities produced and consumed) for goods that enter consumers' preferences symmetrically and which have a one-to-one marginal rate of transformation. That relative price distortion induces an inefficiency in the allocation of resources that remains even in the absence of markup fluctuations. ${ }^{35}$

\footnotetext{
${ }^{33}$ See King and Wolman (1996) for a comprehensive analysis of that long-run tradeoff, as well as a full characterization of the steady state of the Calvo model . Notice that under our baseline calibration, and assuming a frictionless net markup of ten percent $(\mu=0.1)$, the rate of inflation consistent with the efficient level of activity would be about 80 percent per quarter.

${ }^{34}$ In models in which money is an argument in the utility function, that assumption is equivalent to letting the coefficient on real balances approach zero.

${ }^{35}$ Thus, in a steady state with nonzero inflation (and constant average markups), only a fraction of individual prices will be adjusted each period, generating dispersion in relative prices.
} 
Interestingly, it turns out that in the model considered here the two distortions associated with the presence of sticky prices (a) do not generate a policy trade-off, and (b) can be fully corrected through an appropriate monetary policy. The optimal policy requires that the markup of all firms is fully stabilized at its flexible price level. That stabilization will be attained only if the price level is fully stabilized (permanent zero inflation), as implied by (22). In that environment, firms that have an opportunity to readjust their prices choose not to do so; that, in turn, requires that they all charge a common optimal markup $\mu$ and, hence, share identical prices and quantities (implying the absence of a relative price distortion). In other words, the constraint on firms' ability to adjust prices becomes nonbinding, and the flexible price allocation is restored. Along with it, the fact that no firm has an incentive to change its price implies that the path of the aggregate price level is perfectly flat (zero inflation).

In that context, and as shown in Woodford (1999c), the period utility losses resulting from deviations from the flexible price allocation can be approximated by means of the period loss function: ${ }^{36}$

$$
L_{t}=\frac{U_{c} C}{2}\left((\sigma+\varphi) E_{t}\left\{x_{t}^{2}\right\}+\frac{\varepsilon}{\lambda} E_{t}\left\{\pi_{t}^{2}\right\}\right)
$$

Hence, the expected loss of utility resulting from departures from the optimal allocation, expressed as a fraction of steady state consumption, is approximately given

$$
\frac{1}{2}\left((\sigma+\varphi) \operatorname{var}\left(x_{t}\right)+\frac{\varepsilon}{\lambda} \operatorname{var}\left(\pi_{t}\right)\right)
$$

Next I derive and characterize the monetary policy strategy that would minimize those losses, and discuss some issues related to its implementation.

\subsection{Optimal Monetary Policy}

A monetary authority seeking to minimize the loss function (29) does not face any trade-off: it will find it possible to fully stabilize both inflation and the output gap. Thus, the optimal policy requires that:

$$
x_{t}=\pi_{t}=0
$$

all $t$. The resulting allocation under that policy replicates the (efficient) flexible price equilibrium allocation. Given the price stability requirement, the path for the nominal rate consistent with the optimal policy will correspond to that of the real rate in the flexible price equilibrium. Hence, and given (14) the optimal policy implies:

\footnotetext{
${ }^{36}$ See Rotemberg and Woodford (1999) and Woodford (1999c) for a derivation of the approximated welfare loss function under alternative and more general assumptions, respectively.
} 


$$
\begin{aligned}
r_{t} & =\overline{r r}_{t} \\
& =\rho+\sigma \psi_{a} \rho_{a} \Delta a_{t}+\sigma\left(1-\psi_{g}\right)\left(1-\rho_{g}\right) g_{t}
\end{aligned}
$$

where we recall that $\psi_{a}=\frac{1+\varphi}{\sigma+\varphi}$, and $\psi_{g}=\frac{\sigma}{\sigma+\varphi}$. The intuition underlying the optimality of that interest rate response can be easily grasped by considering the adjustment of consumption to both technology and fiscal shocks in the flexible price case (see (12)). Thus, an expansionary fiscal shock lowers consumption on impact, with the reversion to its initial level requiring a higher interest rate. On the other hand, as long as there is positive serial correlation in productivity growth $\left(\rho_{a}>0\right)$, a positive technology shock leads to a gradual adjustment of consumption to its new, higher plateau; supporting that response pattern also requires a higher interest rate. ${ }^{37}$

\subsubsection{Implementation}

Interestingly, however, (30) cannot be interpreted as a monetary policy rule that the central bank could follow mechanically, and which would guarantee that the optimal allocation is attained. In order to see this, notice that, after plugging (30) into (20), the equilibrium dynamics can be represented by means of the difference equation:

$$
\left[\begin{array}{c}
x_{t} \\
\pi_{t}
\end{array}\right]=\mathbf{A}_{\mathbf{O}}\left[\begin{array}{c}
E_{t}\left\{x_{t+1}\right\} \\
E_{t}\left\{\pi_{t+1}\right\}
\end{array}\right]
$$

where

$$
\mathbf{A}_{\mathbf{O}}=\left[\begin{array}{cc}
1 & \sigma^{-1} \\
\kappa & \beta+\kappa \sigma^{-1}
\end{array}\right]
$$

Clearly, $x_{t}=\pi_{t}=0$, for all $t$, constitutes a solution to (31). Yet, a necessary and sufficient condition for the uniqueness of such a solution in a system with no predetermined variables like (31) is that the two eigenvalues of $\mathbf{A}_{\mathbf{O}}$ lie inside the unit circle. ${ }^{38}$ It is easy to check, however, that such a condition is not satisfied in our case. More precisely, while both eigenvalues of $\mathbf{A}_{\mathbf{O}}$ can be shown to be real and positive, only the smallest one lies in the $[0,1]$ interval. As a result there exists a continuum of solutions in a neighborhood of $(0,0)$ that satisfy the equilibrium conditions (local indeterminacy). Furthermore, one cannot rule out the possibility of equilibria displaying fluctuations driven by self-fulfilling revisions in expectations (stationary sunspot fluctuations).

That indeterminacy problem can be avoided, and the uniqueness of the equilibrium allocation restored, by having the central bank follow a rule which would make

\footnotetext{
${ }^{37}$ See Galí, López-Salido and Vallés (2000) for evidence of an efficient response by the Fed to technology shocks during the Volcker-Greenspan period, which contrasts with the inefficient response observed during the pre-Volcker period.

${ }^{38}$ See, e.g., Blanchard and Kahn (1982).
} 
the interest rate respond to inflation and/or the output gap were those variables to deviate from their (zero) target values. More precisely, suppose that the central bank commits itself to following the rule:

$$
r_{t}=\overline{r r}_{t}+\phi_{\pi} \pi_{t}+\phi_{x} x_{t}
$$

In that case, the equilibrium is described by a stochastic difference equation like (31), with $\mathbf{A}_{\mathbf{O}}$ replaced with

$$
\mathbf{A}_{T}=\Omega\left[\begin{array}{cc}
\sigma & 1-\beta \phi_{\pi} \\
\sigma \kappa & \kappa+\beta\left(\sigma+\phi_{x}\right)
\end{array}\right]
$$

where $\Omega=\frac{1}{\sigma+\phi_{x}+\kappa \phi_{\pi}}$.If we restrict ourselves to non-negative values of $\phi_{\pi}$ and $\phi_{x}$, a necessary and sufficient condition for $\mathbf{A}_{T}$ to have both eigenvalues inside the unit circle (thus implying uniqueness of the $(0,0)$ solution to $(31)$ ) is given by ${ }^{39}$

$$
\kappa\left(\phi_{\pi}-1\right)+(1-\beta) \phi_{x}>0
$$

Notice that, once uniqueness is restored, the term $\phi_{\pi} \pi_{t}+\phi_{x} x_{t}$ appended to the interest rate rule vanishes, implying that $r_{t}=\overline{r r}_{t}$ all $t$. Hence, we see that stabilization of the output gap and inflation requires a credible threat by the central bank to vary the interest rate sufficiently in response to any deviations of inflation and/or the output gap from target; yet, the very existence of that threat makes its effective application unnecessary.

\subsubsection{Discussion}

A common argument against the practical relevance of a monetary policy rule like (32) stresses the fact that its implementation requires having far more information than that available to actual central banks. ${ }^{40}$ For one, the specific form of the optimal policy rule is not robust to changes in some of the model characteristics; its correct application thus hinges on knowledge of the true model and of the values taken by all its parameters. In addition, it requires that the central bank be able to observe and respond (contemporaneously) to the realizations of the different shocks ( $a_{t}$ and $g_{t}$, in the present model ). This is not likely to be the case in practice, given the well known problems associated with measurement of variables like total factor productivity, not to mention the practical impossibility of detecting exogenous shifts in some parameters that may be unobservable by nature (e.g., parameters describing preferences) ${ }^{41}$

\footnotetext{
${ }^{39}$ See, e.g., Bullard and Mitra (1999).

${ }^{40}$ See Blinder (1998) for a discussion of the practical complications facing central bankers in the design and implementation of monetary policy.

${ }^{41}$ Given the inherent difficulties in measuring the output gap, the previous argument would also seem to apply to the central bank's need to respond to that variable in order to avoid the indeterminacy problem. But it is clear from (33) that the equilibrium is unique even if $\phi_{x}=0$, so long as $\phi_{\pi}>1$.
} 
The practical difficulties in implementing optimal rules have led many authors to propose a variety of simple rules as possible alternatives, and to evaluate their desirability in the context of one or more models. A large number of recent papers have sought to analyze the properties and desirability of many such rules. ${ }^{42}$ In the next subsection I describe three of them and examine their properties in the context of the baseline sticky price model developed above.

\subsection{Simple Policy Rules}

Here I embed three alternative simple rules in the baseline sticky price model and analyze their basic properties. The following three rules are considered in turn: a Taylor rule, a constant money growth rule, and an interest rate peg.

\subsubsection{A Simple Taylor Rule}

Let us assume that the central bank follows the rule

$$
r_{t}=\rho+\phi_{\pi} \pi_{t}+\phi_{x} x_{t}
$$

i.e., the nominal rate responds systematically to the contemporaneous values of inflation and the output gap. This is a version of the rule put forward by John Taylor as a good characterization of U.S. monetary policy, and analyzed in numerous recent papers. ${ }^{43}$

Combining (34) with (19) and (20), one can represent the equilibrium dynamics with the system:

$$
\left[\begin{array}{c}
x_{t} \\
\pi_{t}
\end{array}\right]=\mathbf{A}_{T}\left[\begin{array}{c}
E_{t}\left\{x_{t+1}\right\} \\
E_{t}\left\{\pi_{t+1}\right\}
\end{array}\right]+\mathbf{B}_{T}\left(\overline{r r}_{t}-\rho\right)
$$

where $\mathbf{A}_{T}$ and $\overline{r r}_{t}$ are defined as above, and $\mathbf{B}_{T}=\Omega[1, \kappa]^{\prime}$. As long as $\phi_{\pi}$ and $\phi_{x}$ satisfy condition (33), the previous system has a unique stationary solution which can be written as:

\footnotetext{
${ }^{42}$ See, e.g., the contributions by several authors contained in theTaylor (1999) volume.

${ }^{43}$ See Taylor $(1993,1999)$ and Judd and Rudebusch (1988). Clarida, Galí, and Gertler (1998, 2000) estimate a forward looking version of that rule, in which the interest rate is assumed to respond to anticipated inflation and output gap, instead of the realized values. Orphanides (1999) discusses the difficulties and perils of implementing a Taylor-type rule in real time.

Strictly speaking, the output component in Taylor's original rule involves the percent deviations of output from a smooth (linear) trend. In the model considered here, such deviations are permanent since output has a unit root in equilibrium, implying that there is no deterministic trend or steady state value that output reverts to. As a consequence, a rule of that sort would prevent the economy from adjusting to its long run equilibrium path. On the other hand, the output gap $\left\{x_{t}\right\}$ follows a stationary process, so that its inclusion in the rule will not lead to permanent deviations of the interest rate from its natural level.
} 


$$
\left[\begin{array}{c}
x_{t} \\
\pi_{t}
\end{array}\right]=\omega_{a}\left[\mathbf{I}-\rho_{a} \mathbf{A}_{T}\right]^{-1} \mathbf{B}_{T} \Delta a_{t}+\omega_{g}\left[\mathbf{I}-\rho_{g} \mathbf{A}_{T}\right]^{-1} \mathbf{B}_{T} g_{t}
$$

where $\omega_{a}=\sigma \psi_{a} \rho_{a}$ and $\omega_{g}=\sigma\left(1-\psi_{g}\right)\left(1-\rho_{g}\right){ }^{44}$

Notice that in the particular case that both $a_{t}$ and $g_{t}$ follow a pure random walk $\left(\rho_{a}=0, \rho_{g}=1\right)$, we have $x_{t}=\pi_{t}=0$, all $t$; i.e. the Taylor rule supports the optimal allocation. The reason is simple: the Taylor rule will implement the efficient allocation only if the latter is supported by a constant (natural) real rate, as is the case under the random walk assumption.

For more general driving processes, a monetary authority following a rule of the form (34) could minimize the deviations from the optimal path by choosing sufficiently large values of $\phi_{\pi}$ and/or $\phi_{x}{ }^{45}$ A Taylor rule with very high inflation or output gap coefficients, however, would potentially lead to huge instrument-instability: any small deviation of inflation or the output gap from zero (perhaps resulting from small measurement errors or imperfect credibility) would imply infinite changes in the rate. ${ }^{46}$

If $\rho_{a} \in(0,1)$ and/or $\rho_{g} \in(0,1)$, however, no finite values of the coefficients in rule (34) will replicate the optimal responses of output and inflation. The reason is straightforward: supporting the optimal response requires that prices remain stable and that the real and -given zero inflation- and nominal rates change according to (30) in response to technology and fiscal shocks. But a Taylor rule will not generate a change in the nominal rate unless a deviation from the optimal response arises in the form of a nonzero inflation or output gap.

In order to get a sense of the quantitative effects on macroeconomic stability and welfare of having a central bank follow a simple Taylor rule (instead of the optimal one), I have computed the standard deviations of inflation and the output gap predicted by a calibrated version of the sticky price model. I set $\phi_{\pi}=1.5$ and $\phi_{x}=$ 0.5, as in Taylor's original empirical rule. As argued above, avoiding the replication of the efficient allocation requires some departure from the random walk assumption for the driving variables. I set $\rho_{a}=0.25$ and $\sigma_{a}=0.01$, which roughly correspond to the first order serial correlation of U.S. GDP growth, and to the standard deviation of the Solow residual innovations, respectively. In order to calibrate $\rho_{g}$ and $\sigma_{g}$, I fit an $\mathrm{AR}(1)$ model to $g_{t}=-\log \left(1-\tau_{t}\right)$, using the ratio of government purchases to GDP in the U.S. as the empirical counterpart to $\tau_{t}$. That procedure yields values $\rho_{g}=0.95$ and $\sigma_{g}=0.0036$. The remaining parameters are set at their baseline values,

\footnotetext{
${ }^{44}$ Given $x_{t}$, the equilibrium process for output and employment can be determined using the fact that $y_{t}=x_{t}+y_{t}^{*}, c_{t}=x_{t}+c_{t}^{*}$, and $n_{t}=x_{t}+n_{t}^{*}$, with $y_{t}^{*}, c_{t}^{*}$, and $n_{t}^{*}$ given by (11), (12), and (13).

${ }^{45}$ Formally, this is the case because $\Omega$ (and, hence, $\mathbf{B}_{T}$ ) converges to zero as $\phi_{\pi}$ or $\phi_{x}$ approach infinity.

${ }^{46}$ Furthermore, the lack of credibility of such a policy might be more than warranted since it would easily hit the zero-bound on the nominal rate.
} 
but results are also reported for two parameter variations: a calibration with higher risk aversion $(\sigma=5)$, as well as one with weaker nominal rigidities $(\theta=0.5)$.

The first set of columns in Table 1 displays some summary statistics for the resulting equilibrium. In the baseline case the volatility of both inflation and the output gap is extremely small, independently of the type shock; as a result the implied welfare losses associated with the deviations from the efficient allocation are tiny, amounting to less than one hundredth of a percent of steady state consumption. Things do not change dramatically when we increase the degree of risk aversion (second panel) or lower the degree of price stickiness (third panel); most noticeably, however, the volatility of inflation increases in both cases while that of the output gap decreases. Either way, the utility losses resulting from following a Taylor rule instead of the optimal one remain very small.

\subsubsection{Money Growth Peg}

Next I study the consequences of having the monetary authority maintain a constant rate of growth for the money supply, in the face of both supply and demand shocks. Without loss of generality, and for consistency with the steady state with zero inflation and no secular output growth, I assume $\Delta m_{t}=0$, for all $t$. After defining $m p y_{t}=$ $m_{t}-p_{t}-\bar{y}_{t}$, one can represent the equilibrium dynamics under that specification of monetary policy by means of the stationary system:

$$
\begin{aligned}
{\left[\begin{array}{ccc}
1+\frac{1}{\sigma \eta} & 0 & 0 \\
-\kappa & 1 & 0 \\
0 & -1 & 1
\end{array}\right]\left[\begin{array}{c}
x_{t} \\
\pi_{t} \\
m p y_{t-1}
\end{array}\right]=} & {\left[\begin{array}{ccc}
1 & \frac{1}{\sigma} & \frac{1}{\sigma \eta} \\
0 & \beta & 0 \\
0 & 0 & 1
\end{array}\right]\left[\begin{array}{c}
E_{t}\left\{x_{t+1}\right\} \\
E_{t}\left\{\pi_{t+1}\right\} \\
m p y_{t}
\end{array}\right] } \\
& +\left[\begin{array}{ccc}
\psi_{a} \rho_{a} & \left(1-\psi_{g}\right)\left(1-\rho_{g}\right) & 0 \\
0 & 0 & 0 \\
\psi_{a} & \psi_{g} & -\psi_{g}
\end{array}\right]\left[\begin{array}{c}
\Delta a_{t} \\
g_{t} \\
g_{t-1}
\end{array}\right]
\end{aligned}
$$

The second set of columns in Table 1 summarizes some of the statistical properties of the resulting equilibrium. The volatility of both inflation and the output gap resulting from technology shocks is substantially greater than that observed under a Taylor rule, whereas the difference is less pronounced for demand shocks. The welfare losses are no longer negligible, amounting to one quarter of a percent of steady state consumption when both shocks are operative.

\subsubsection{Interest Rate Peg}

The third rule considered here consists of pegging the nominal interest rate at a level $r_{t}=\rho$, i.e. the level consistent with a zero steady state inflation. If interpreted as a rule followed mechanically by the central bank, such a specification of monetary policy is only a particular case of a simple Taylor rule with $\phi_{\pi}=\phi_{x}=0$. But, as argued above, such configuration of parameters renders the equilibrium indeterminate. 
What rule would support a constant nominal rate while guaranteeing determinacy? Consider the following candidate:

$$
r_{t}=\rho+\phi_{r}\left(\pi_{t}+\sigma \Delta c_{t}\right)
$$

where $\phi_{r}>1$. Combining the previous rule with (4) yields the difference equation

$$
\pi_{t}+\sigma \Delta c_{t}=\phi_{r}^{-1} E_{t}\left\{\pi_{t+1}+\sigma \Delta c_{t+1}\right\}
$$

whose only stationary solution satisfies $\pi_{t}=-\sigma \Delta c_{t}$, which in turn implies a constant nominal rate $r_{t}=\rho$, for all $t$. Rule (35) can be viewed as a modified Taylor rule, with consumption growth replacing the output gap. In addition, the inflation and consumption growth coefficients must satisfy a certain proportionality condition: the size of the coefficient on consumption must be exactly $\sigma$ times that of inflation (which in turn must be greater than one). Notice also that the assumption of log utility $(\sigma=1)$ combined with the absence of fiscal shocks $\left(\Delta c_{t}=\Delta y_{t}\right)$ implies a constant nominal GDP; in that case an interest rate peg is equivalent to strict nominal income targeting, and both can be implemented by (35).

Using the fact that $\pi_{t}=-\sigma\left(\Delta x_{t}+\Delta c_{t}^{*}\right)$, combined with (19) and (12), one can represent the equilibrium dynamics by the system:

$$
\left[\begin{array}{c}
\pi_{t} \\
x_{t} \\
x_{t-1}
\end{array}\right]=\left[\begin{array}{ccc}
\beta & 0 & \kappa \\
0 & 0 & 1 \\
0 & -\beta & 1+\beta+\frac{\kappa}{\sigma}
\end{array}\right]\left[\begin{array}{c}
E_{t}\left\{\pi_{t+1}\right\} \\
E_{t}\left\{x_{t+1}\right\} \\
x_{t}
\end{array}\right]+\left[\begin{array}{ccc}
0 & 0 & 0 \\
0 & 0 & 0 \\
b_{1} & b_{2} & b_{3}
\end{array}\right]\left[\begin{array}{c}
\Delta a_{t} \\
g_{t} \\
g_{t-1}
\end{array}\right]
$$

where $b_{1}=\psi_{a}\left(1-\beta \rho_{a}\right), b_{2}=-\left(1-\psi_{g}\right)\left(1+\beta\left(1-\rho_{a}\right)\right)$, and $b_{3}=\left(1-\psi_{g}\right)$.

The third vertical panel in Table 1 reports the volatility of output and inflation as well as the welfare losses under an interest rate peg. Notice that, under the assumption of $\sigma=1$, and conditional on technology shocks being the only source of fluctuations, the statistics shown match exactly those under a money growth peg. This is no coincidence: in that case a constant money growth implies a constant nominal rate, and viceversa; accordingly the resulting allocations are identical and, as discussed above, they are characterized by sizable fluctuations in both the output gap and inflation. In the high risk aversion case $(\sigma=5)$ that equivalence no longer holds, and the deviations from the optimal allocation are more pronounced under the interest rate peg (the welfare losses in the latter case get close to half a percent of steady state consumption). When demand shocks are the source of fluctuations, the performance of an interest rate peg is uniformly worse than a money growth peg, and far worse than a Taylor rule.

\subsubsection{Discussion}

The analysis above has sought to illustrate, in the context of a basic sticky price model, some of the results on the properties of simple rules found in the literature. Some general lessons can be drawn. 
First, supporting as an equilibrium the combination of prices and quantities that the central bank seeks to attain-in our case, the flexible price allocation with zero inflation-generally requires (possibly large) variations in both interest rates and monetary aggregates. Hence, simple policy rules that keep one of those variables constant is likely to cause significant deviations from the desired outcome.

Second, we expect that in the target allocation the pattern of response of interest rates and monetary aggregates will generally differ across shocks. Hence, the fact that a simple rule provides a good approximation to the optimal policy conditional on a certain source of fluctuations does not guarantee a good performance if other shocks become dominant.

Third, a simple interest rate rule à la Taylor does a remarkably good job at approximating the outcome of the optimal policy in a calibrated version of the basic sticky price model. A similar result can be found in a variety of papers that use related, but not identical, frameworks. Furthermore, several authors have emphasized the robustness of the Taylor rule across a variety of models, relative to more complex policy rules (including those that are optimal for some model).$^{47}$

A key feature of the simple Taylor rule considered here is that it makes the interest rate respond (in a stabilizing direction) to deviations from target in inflation and the output gap, i.e. precisely the variables that enter the loss function used to evaluate alternative policies. That feature underlies, undoubtedly, the good performance of the rule. From that point of view, it is worth noting that the specification of a simple Taylor rule used here is likely to be more desirable than an alternative, more conventional one, in which the interest rate is assumed to respond to deviations of output from trend (instead of its deviation from its natural rate). As stressed in McCallum and Nelson (1999), Rotemberg and Woodford (1999) and Galí (2000), a strong response to (detrended) output may be highly inefficient when shocks to fundamentals call for large changes in output. The output gap induced by such a policy will, in turn, lead to unnecessary fluctuations in inflation. It is not surprising, thus, that a pure inflation targeting rule (i.e., one with little or no weight attached to output stabilization) may often do better than one which is also concerned about output stabilization. ${ }^{48}$

\footnotetext{
${ }^{47}$ See, among others, Ireland (2000), Rudebusch and Svensson (1999), Levin, Wieland and Williams (1999), Rotemberg and Woodford (1999), Galí, López-Salido and Vallés (2000).

${ }^{48}$ Orphanides (1999) stresses an additional advantage of an inflation targeting rule: it avoids the risks associated with having the monetary authority respond to output gap indicators ridden with large and persistent measurement error. According to Orphanides' analysis that problem may have been at the root of the great inflation of the $70 \mathrm{~s}$ in the US.
} 


\subsection{Optimal Monetary Policy in the Presence of an Output Gap/Inflation Tradeoff}

As discussed earlier, the baseline sticky price model analyzed above embeds no tradeoff between inflation and output gap stabilization: by following an appropriate policy, the monetary authority can attain the efficient allocation, i.e., the one corresponding to an equilibrium in which both inflation and the output gap are constant.

The lack of an inflation/output tradeoff is viewed by many economists as an unappealing feature of the previous framework. That consideration has led some authors to amend the basic model in a way which adds some realism to the policymaker's problem, while preserving the tractability of the original model. ${ }^{49}$ A simple, largely ad-hoc, way to achieve that objective is to augment the inflation equation with a disturbance that generates a trade-off between inflation and the output gap. Formally:

$$
\pi_{t}=\beta E_{t}\left\{\pi_{t+1}\right\}+\kappa x_{t}+u_{t}
$$

where $u_{t}$ is a shock that implies a change in the equilibrium level of inflation consistent with the natural level of output. That shock is often referred to in the literature as a cost-push shock. For simplicity I assume that $\left\{u_{t}\right\}$ follows a white noise process with a zero mean and variance $\sigma_{u}^{2}$. The existence of a tradeoff can be seen clearly by solving (36) forward, which yields:

$$
\pi_{t}=\kappa \sum_{k=0}^{\infty} \beta^{k} E_{t}\left\{x_{t+k}\right\}+u_{t}
$$

Thus, an adverse cost-push shock (a positive realization in $u_{t}$ ) necessarily leads to a rise in inflation, and/or a negative output gap (current or anticipated).

Consider, as a benchmark, the macroeconomic and welfare implications of a monetary policy that would fully accommodate the inflationary effects of a cost-push shock, by maintaining output at its natural level at all times. In that case we would have $x_{t}=0$ and $\pi_{t}=u_{t}$ for all $t$. Using (29) we can derive an expression for the expected welfare loss (expressed as a percent of steady state consumption) incurred under the fully accommodating policy:

$$
\frac{\varepsilon \sigma_{u}^{2}}{2 \lambda} \times 100
$$

If we normalize the standard deviation of the shock to be one percent $\left(\sigma_{u}=0.01\right)$, we see that under the baseline calibration that welfare loss (relative to the efficient allocation) amounts to $0.64 \%$ of steady state consumption.

Of course, there is no reason why a central bank would want to accommodate fully a cost-push shock. Instead, it will want to respond to such a shock so that the

\footnotetext{
${ }^{49}$ See, e.g., Clarida, Galí, and Gertler (1999).
} 
resulting path of inflation and the output gap minimizes the utility loss. Formally, and given (28), the central bank will seek to minimize

$$
E_{0}\left\{\sum_{t=0}^{\infty} \beta^{t}\left[\kappa x_{t}^{2}+\varepsilon \pi_{t}^{2}\right]\right\}
$$

subject to the sequence of budget constraints (36). Given the resulting optimal path for $\left\{x_{t}, \pi_{t}\right\}$ we can use (20) to derive the interest rate policy that would support such a path.

The form of the solution to the above problem depends critically on the assumptions we make regarding the central bank's ability to commit to future policy actions. Below I describe the optimal policy and its macroeconomic implications under two alternative, polar assumptions: discretion vs. commitment.

Before turning to the formal analysis it is important to stress the connection between the results presented here and the early literature on credibility and gains from commitment. The latter, exemplified by the work of Kydland and Prescott (1977), Barro and Gordon (1983), and Rogoff (1985), brought to light the risk of a persistent inflation bias arising from the central bank's inability to commit to a low inflation policy. In their framework, the ultimate source of that bias could be found in the central bank's desire to push output above its natural (flexible price) level, presumably because the latter is inefficiently low. ${ }^{50}$ Without such a bias an efficient outcome characterized by zero output and zero inflation can be attained under discretion. In other words, in the absence of an inflation bias there would not be any gains from commitment.

In the optimizing sticky price model considered here, the previous result no longer holds. Instead, and as shown in Clarida, Galí, and Gertler (1999) and Woodford (1999b), even in the absence of an inflation bias there are potential welfare gains associated with the central bank's ability to commit credibly to a systematic pattern of response to shocks that generate a tradeoff between output and inflation. Next I show that result using the baseline NK model.

\subsubsection{Optimal Discretionary Policy}

Suppose that the monetary authority cannot credibly commit to any future policy actions. Since it is unable to influence current expectations on future output and inflation, it has to take those expectations as given. Accordingly, each period it will choose $\left(x_{t}, \pi_{t}\right)$ in order to minimize

$$
\kappa x_{t}^{2}+\varepsilon \pi_{t}^{2}
$$

subject to

$$
\pi_{t}=\kappa x_{t}+\theta_{t}
$$

\footnotetext{
${ }^{50}$ In that case the terms involving $x_{t}^{2}$ in the loss function are replaced with $\left(x_{t}-x^{*}\right)^{2}$ where $x^{*}>0$ denoted the output gap target.
} 
where $\theta_{t}=\beta E_{t}\left\{\pi_{t+1}\right\}+u_{t}$ is taken as given by the central bank. The solution to the problem above must satisfy:

$$
x_{t}=-\varepsilon \pi_{t}
$$

Substituting (38) into (36), and solving the resulting difference equation forward yields:

$$
\begin{gathered}
\pi_{t}=\left(\frac{1}{1+\kappa \varepsilon}\right) u_{t} \\
x_{t}=-\left(\frac{\varepsilon}{1+\kappa \varepsilon}\right) u_{t}
\end{gathered}
$$

Hence, in response to an adverse cost-push shock the central bank finds it optimal to engineer a temporary reduction in output, thus dampening the effect of the shock on inflation. The incentive to "split" the effects of the shock between output and inflation is a consequence of the convexity of the loss function in those variables.

The expected welfare loss under the optimal discretionary policy is given by:

$$
\frac{\varepsilon \sigma_{u}^{2}}{2 \lambda(1+\kappa \varepsilon)} \times 100
$$

which is always lower than the loss under the fully accommodating policy.

Under the baseline calibration the standard deviations of the output gap and (annualized) inflation when the central bank pursues the optimal discretionary policy are $3.80 \%$ and $1.38 \%$, respectively. The implied welfare loss amounts now to 0.22 $\%$ of steady state consumption.

Using (20), we see that the implied equilibrium interest rate under the optimal discretionary policy is given by:

$$
r_{t}=\overline{r r}_{t}+\left(\frac{\sigma \varepsilon}{1+\kappa \varepsilon}\right) u_{t}
$$

Notice that a simple interest rate rule that would support (39) and (40) is given by:

$$
r_{t}=\overline{r r}_{t}+\sigma \varepsilon \pi_{t}
$$

As discussed earlier, the previous rule will guarantee that the desired allocation obtains if and only if $\sigma \varepsilon>1$, a condition that is satisfied for plausible values of those parameters. Alternatively, a rule of the form

$$
r_{t}=\overline{r r}_{t}+\left(\frac{\sigma \varepsilon-\phi_{\pi}}{1+\kappa \varepsilon}\right) u_{t}+\phi_{\pi} \pi_{t}
$$

with $\phi_{\pi}>1$ will always guarantee uniqueness of the equilibrium. 


\subsubsection{Optimal Policy With Commitment}

Suppose that the monetary authority can choose, once and for all, a state-contingent policy $\left\{x\left(z^{t}\right), \pi\left(z^{t}\right)\right\}_{t=0}^{\infty}$ where $z^{t}$ denotes the history of shocks up to period $t$, and assume it sticks to its plan. The equilibrium dynamics for the output gap and inflation under the optimal policy with commitment can be shown to satisfy the optimality condition: ${ }^{51}$

$$
x_{t}=-\varepsilon\left(p_{t}-p^{*}\right)
$$

for $t=0,1,2, \ldots$ where $p^{*}$ can be interpreted as a price level target, which corresponds to the (log) price level in the period before the monetary authority chooses (once and for all) its optimal plan (i.e., $p^{*}=p_{-1}$ ).

Combining (42) with (36), one can derive a stochastic difference equation for the output gap implied by the optimal policy:

$$
x_{t}=a x_{t-1}+a \beta E_{t}\left\{x_{t+1}\right\}-a \varepsilon u_{t}
$$

for $t=0,1,2, \ldots$ where $a=\frac{1}{1+\beta+\kappa \varepsilon}$. The (nonexplosive) solution to the previous difference equation is given by:

$$
x_{t}=\delta x_{t-1}-\varepsilon \psi_{u} u_{t}
$$

where $\delta=\frac{1-\sqrt{1-4 \beta a^{2}}}{2 a \beta} \in(0,1)$ and $\psi_{u}=a\left(1+\beta \delta^{2}\right)$. We can then use (42) to derive the equilibrium process for $\widetilde{p}_{t}=p_{t}-p^{*}$, the deviation of the price level from target:

$$
\widetilde{p}_{t}=\delta \widetilde{p}_{t-1}+\psi_{u} u_{t}
$$

Thus, we see that the optimal policy with commitment implies a stationary process for the price level, i.e., the deviations of the price level from the target level $p^{*}$ are only transitory, with any inflation resulting from a cost-push shock being eventually followed by deflation.

The pattern of responses for (annualized) inflation and the output gap under commitment is depicted graphically in Figure 7, which also displays the responses under the optimal discretionary policy. The figure illustrates two aspects of the differences in outcome that are worth pointing out. First, one can show that the possibility of commitment improves the terms of the output-inflation trade-off facing the policymaker. This is illustrated in Figure 7 where we see that the increase in inflation resulting from a unit cost-push shock is smaller under commitment than under discretion, even though the associated decline in the output gap is also smaller. That result has a simple explanation, directly related to the forward-looking nature

\footnotetext{
${ }^{51}$ See Woodford (1999b) and Clarida, Galí, and Gertler (1999) for a derivation. The latter paper also analyzes the (simpler) case of commitment under the constraint that both the output gap and inflation are a function of the current state only, not of its entire history.
} 
of inflation: the response of inflation to a cost-push shock depends on the anticipated path for the output gap. Under discretion, the output gap returns to zero once the shock dies out. Accordingly, the initial response of inflation is proportional to the initial decline in the output gap, given the shock. By way of contrast, under commitment the output gap remains negative well after the direct effects of the shock have vanished, and returns to its initial level only asymptotically; the anticipation of that low level of economic activity in the future has, in itself, a dampening effect on inflation, thus explaining the smaller rise of inflation under commitment, despite the smaller decline in output.

Second, it is clear that the joint pattern of output and inflation under commitment in the periods following the shock is time-inconsistent. Since both inflation and the output gap take on negative values (and thus generate a welfare loss), it would be optimal (as well as feasible) for a central bank that did not feel restrained by its earlier promises to pursue a more expansionary policy and to restore the efficient allocation.

Since the optimal discretionary policy falls within the range of feasible policies available to a policymaker with access to a commitment technology, it is not surprising that the welfare losses associated with the optimal policy with commitment are smaller than in the discretion case. Thus, for instance, under our baseline calibration, the welfare loss represents $0.17 \%$ of steady state consumption (compared to $0.22 \%$ in the discretionary case). Underlying that loss in welfare in the numerical example, we have a standard deviations of the output gap and (annualized) inflation given by $3.17 \%$ and $1.39 \%$, respectively (compared to $3.80 \%$ and $1.38 \%$ under discretion).

\section{$6 \quad$ Staggered Wage Setting}

The analysis up to this point has been based on a stylized model in which imperfect competition and sticky prices in the goods market coexist with a labor market characterized by perfect competition and flexible wages. Up until recently, that was the framework that seemed to be favored in macroeconomic analysis. One possible reason for that choice may be that an alternative framework which emphasized wage stickiness (and perfectly competitive good markets) would tend to predict, counterfactually, a procyclical behavior of real wages, at least if demand shocks were the dominant source of fluctuations.

Yet, several authors have studied recently the consequences of introducing nominal rigidities (with or without price rigidities) in a dynamic general equilibrium framework. In the present section I lay out an extension of the baseline sticky price model that incorporates staggered wage setting. ${ }^{52}$

\footnotetext{
${ }^{52}$ Blanchard and Kiyotaki (1987) contains an early analysis of a static model with both wage and price stickiness. The model developed here is a simplified version of the one analyzed in Erceg, Henderson, and Levin (2000). Kim (2000) develops a model in a similar spirit, but where the stickiness of wages and prices results from the existence of adjustment costs. Erceg (1997) and
} 


\subsection{A Simple Model of Staggered Wage and Price Setting}

Consider a continuum of labor types, indexed by $j \in[0,1]$. The effective labor input in the production process of a typical firm is given by a CES function of the quantities of different types of labor hired. Thus for firm $i$ :

$$
N_{i t}=\left(\int_{0}^{1} N_{i t}(j)^{\frac{\varepsilon_{w}-1}{\varepsilon_{w}}} d j\right)^{\frac{\varepsilon_{w}}{\varepsilon_{w}-1}}
$$

where $\varepsilon_{w}>1$ is the elasticity of substitution between labor types in production.

The quantity of labor of type $j$ demanded by firm $i$ is given by

$$
N_{i t}(j)=\left(\frac{W_{t}(j)}{W_{t}}\right)^{-\varepsilon_{w}} N_{i t}
$$

where $W_{t}(j)$ is the cost of hiring one unit of type $j$ labor and $W_{t}=\left(\int_{0}^{1} W_{t}(j)^{1-\varepsilon_{w}} d j\right)^{\frac{1}{1-\varepsilon_{w}}}$ is an aggregate wage index.

Each household specializes in supplying a differentiated type of labor. Total demand for labor of type $j, N_{t}(j)=\int_{0}^{1} N_{i t}(j) d i$ is given by

$$
N_{t}(j)=\left(\frac{W_{t}(j)}{W_{t}}\right)^{-\varepsilon_{w}} N_{t}
$$

where $N_{t}=\int_{0}^{1} N_{i t} d i$ denotes aggregate labor input.

If all households could set their wage optimally every period they would do so according to the log-linear rule $w_{t}=\mu_{w}+m r s_{t}+p_{t}$, where $\mu_{w}=\log \left(\frac{\varepsilon_{w}}{\varepsilon_{w}-1}\right)$ represents the desired markup of the real wage over the marginal rate of substitution between consumption and leisure $m r s_{t}=\sigma c_{t}+\varphi n_{t}$.

Staggered wage setting is introduced by assuming that each household faces a probability $\theta_{w}$ of having to keep the wage for its labor type unchanged in any given period. Let $w_{t}^{*}$ denote the (log) wage set by households adjusting wages in period $t$. The evolution of the aggregate wage level over time can be approximated by the log-linear difference equation:

$$
w_{t}=\theta_{w} w_{t-1}+\left(1-\theta_{w}\right) w_{t}^{*}
$$

One can show that optimizing households will set their wage according to the (approximate) log-linear rule

$$
w_{t}^{*}=\mu_{w}+\left(1-\beta \theta_{w}\right) \sum_{k=0}^{\infty}\left(\beta \theta_{w}\right)^{k} E_{t}\left\{m r s_{t, t+k}+p_{t+k}\right\}
$$

Huang and Liu (1999) analyze the effects of exogenous monetary policy shocks in a model with wage contracts à la Taylor. 
where $m r s_{t, t+k}=\sigma c_{t+k}+\varphi n_{t, t+k}$, with $n_{t, t+k}$ being the quantity of labor supplied in period $t+k$ by a household whose wage was last reset in period $t .^{53}$ The intuition behind the previous wage setting rule is analogous to that for price setting: households (workers) will set the nominal wage so that a weighted average of the expected wage markup over the duration of the contract matches the frictionless optimal markup $\mu_{w}$.

Using the fact that

$$
n_{t, t+k}=-\varepsilon_{w}\left(w_{t}^{*}-w_{t+k}\right)+n_{t}
$$

one can rewrite (46) in terms of aggregate variables as follows:

$$
w_{t}^{*}-w_{t}=-\left(\frac{1-\beta \theta_{w}}{1+\varphi \varepsilon_{w}}\right) \sum_{k=0}^{\infty}\left(\beta \theta_{w}\right)^{k} E_{t}\left\{\widehat{\mu}_{t+k}^{w}\right\}+\sum_{k=1}^{\infty}\left(\beta \theta_{w}\right)^{k} E_{t}\left\{\pi_{t+k}^{w}\right\}
$$

where $\widehat{\mu}_{t}^{w}=\left(w_{t}-p_{t}\right)-m r s_{t}-\mu^{w}$ can be interpreted as the percent deviation between the average wage markup and its frictionless level.

Combining (45) and (47) we obtain the wage inflation equation:

$$
\pi_{t}^{w}=\beta E_{t}\left\{\pi_{t+1}^{w}\right\}-\lambda_{w} \widehat{\mu}_{t}^{w}
$$

where $\lambda_{w}=\frac{\left(1-\beta \theta_{w}\right)\left(1-\theta_{w}\right)}{\theta_{w}\left(1+\varphi \varepsilon_{w}\right)}$. Notice also the following relationship between the wage markup and the real marginal cost:

$$
\begin{aligned}
m c_{t} & =\left(w_{t}-p_{t}\right)-a_{t} \\
& =\mu_{t}^{w}+m r s_{t}-a_{t} \\
& =\mu_{t}^{w}+(\sigma+\varphi) y_{t}-(1+\varphi) a_{t}-\sigma g_{t}
\end{aligned}
$$

It follows that $\widehat{m c}_{t}=(\sigma+\varphi) x_{t}+\widehat{\mu}_{t}^{w}$, where $x_{t}$ denotes the (log) deviation of output from its level in the absence of both price and wage rigidities. ${ }^{54}$

One can combine the previous results with (17) (whose derivation was independent of the presence or not of wage rigidities), to obtain a version of the New Phillips Curve for an economy with staggered wage setting

$$
\pi_{t}=\beta E_{t}\left\{\pi_{t+1}\right\}+\kappa x_{t}+\lambda \widehat{\mu}_{t}^{w}
$$

Interestingly, (49) seems to provide a theoretical justification for the inclusion of the cost-push disturbance in (36), as a way to generate a trade-off between output and inflation. Yet, an important difference remains: the disturbance thus generated

\footnotetext{
${ }^{53}$ Notice that the level of consumption is the same across households, as a result of risk sharing.

${ }^{54}$ Equivalently, we see that $x_{t}=-\frac{\widehat{\mu}_{t}^{p}+\widehat{\mu}_{t}^{w}}{\sigma+\varphi}$, i.e., the output gap is proportional to the sum of the deviations of the price and wage markups from their steady state levels. Since $\widehat{\mu}_{t}^{p}+\widehat{\mu}_{t}^{w}=m r s_{t}-a_{t}$, it follows that the output gap is proportional to the wedge between the marginal rate of substitution between consumption and labor and the corresponding marginal rate of transformation, and hence it is a measure of the (uncorrected) aggregate distortions in the economy.
} 
cannot be assumed to be exogenous, since it will generally depend on preference and technology parameters, as well as on the underlying disturbances. ${ }^{55}$

\subsubsection{A Particular Case: Sticky Wages and Flexible Prices}

Consider the polar case with sticky wages but fully flexible prices. In that case all firms face identical marginal costs and charge identical prices, consistent with the desired markup (i.e., $\widehat{\mu}_{t}^{p}=0$ ). As a result there is no relative price distortion and the variance of price inflation should no longer be a central bank's concern. In that case it is possible for the central bank to replicate the flexible price and wage allocation by having $\widehat{\mu}_{t}^{w}=\pi_{t}^{w}=x_{t}=0$, for all $t$. It follows that price inflation under the optimal policy will be given by $\pi_{t}=-\Delta a_{t}$, for all $t$. The prescription of full price stabilization is no longer desirable in that environment; the monetary authority should seek to stabilize wages instead.

The nominal rate that will support that efficient allocation will have to satisfy:

$$
\begin{aligned}
r_{t} & =\overline{r r}_{t}+E_{t}\left\{\pi_{t+1}\right\} \\
& =\rho+\frac{(\sigma-1) \varphi \rho_{a}}{\sigma+\varphi} \Delta a_{t}+\sigma\left(1-\psi_{g}\right)\left(1-\rho_{g}\right) g_{t}
\end{aligned}
$$

\subsection{Optimal Monetary Policy When Both Wages and Prices Are Sticky}

Can the allocation associated with flexible prices and wages be restored when both prices and wages are sticky ? The answer is no, as shown in Erceg, Henderson, and Levin (2000; henceforth EHL). The reason is straightforward: replicating that allocation requires $\widehat{\mu}_{t}^{p}=\widehat{\mu}_{t}^{w}=0$, for all $t$. It would then follow from (17) and (48) that $\pi_{t}^{w}=\pi_{t}=0$, which in turn implies a constant real wage. But that is inconsistent with the requirement that the real wage adjusts on a one-to-one basis with the marginal product of labor and the marginal rate of substitution if the real marginal cost and the wage markup are to remain constant. To the extent that the equilibrium in the model with flexible wages and prices involves fluctuations in either variable (as it will generally be the case), the efficient allocation will not be attainable.

Given the existence of a tradeoff between stabilization of the output gap, price inflation and wage inflation, what is the appropriate course of action for a policymaker seeking to maximize consumers' welfare ? EHL have derived the loss function for an economy with wage and price stickiness, thus generalizing the analysis of Rotemberg and Woodford. The resulting loss function, expressed as a fraction of steady state consumption, is given by:

\footnotetext{
${ }^{55}$ See Erceg, Henderson, and Levin (2000).
} 


$$
-\frac{1}{2}\left((\sigma+\varphi) \operatorname{var}\left(x_{t}\right)+\frac{\varepsilon}{\lambda} \operatorname{var}\left(\pi_{t}\right)+\frac{\varepsilon_{w}}{\lambda_{w}} \operatorname{var}\left(\pi_{t}^{w}\right)\right)
$$

Notice that $\lambda$ and $\lambda_{w}$ are decreasing in the degree of price and wage rigidities (respectively), as parameterized by $\theta_{p}$ and $\theta_{w}$. Hence, the monetary authority will attach a relatively greater weight to price (wage) inflation stabilization the stronger (weaker) price rigidities are relative to wage rigidities. ${ }^{56}$ The baseline sticky price model analyzed in the previous sections corresponds to the limiting case $\lambda_{w} \rightarrow+\infty$, so that wage inflation stabilization stops being a concern (a symmetric result hold for the flexible price case). Notice that the welfare loss associated with a given level of price or wage inflation is proportional to the elasticities of substitution among different goods and different types of labor, respectively. That result reflects the fact that the degree of substitutability will enhance the (inefficient) dispersion in output and employment levels generated by the staggering of prices and/or wages in an environment with nonzero inflation.

EHL (2000) use numerical methods to derive the optimal policy rule in an economy similar to the one just described, and determine the implied volatility of the output gap, price inflation and wage inflation, as well as the associated welfare losses. Among other results, they show that when prices are more (less) rigid than wages, the optimal policy requires that wages (prices) account for a relatively larger share of the real wage adjustment; as a consequence, the rate of inflation of the more flexible variable ends up displaying higher volatility (in a way consistent with its smaller weight in the loss function). EHL also show that, for a variety of calibrations, simple rules that put a lot of weight on wage inflation and/or output gap stabilization perform nearly as well as the optimal one.

\section{Concluding Remarks}

The present paper has surveyed a number of results generated by recent research on monetary policy in dynamic optimizing models with nominal rigidities. In my opinion, that research program has yieded several new insights, as well as a number of results that one may view as surprising, regarding the linkages between monetary policy, inflation and the business cycle. In other words, and contrary to what some economists might have predicted, the effort to integrate Keynesian-type elements into a dynamic GE framework has gone beyond "providing rigorous microfoundations" to some preexisting, though largely ad-hoc, framework. Furthermore, that research program is making significant progress towards the development of a standard framework that can be used meaningfully for the purpose of evaluating alternative monetary policies.

\footnotetext{
${ }^{56}$ Benigno (1999) obtains a related result when analyzing the optimal policy in a monetary union: the central bank should put more weight to stabilization of the rate of inflation in the economy facing stronger nominal rigidities.
} 
Perhaps the clearest proof of that potential lies in the renewed interest shown by many central banks in the recent academic research on monetary economics. 


\section{References}

Andersen, Torben M. (1998): "Persistency in Sticky Price Models," European Economic Review 42, 1998, 593-603.

Andrés, Javier, David López-Salido, and Javier Vallés (1999): "Intertemporal Substitution and the Liquidity Effect in a Sticky Price Model," Bank of Spain, mimeo.

Basu, Susanto, John Fernald, and Miles Kimball (1998): "Are Technology Improvements Contractionary ?" mimeo.

Benigno, Pierpaolo (1999): "Optimal Monetary Policy in a Currency Area," mimeo.

Bergin, Paul R. and Robert C. Feenstra (2000): "Staggered Price Setting, Translog Preferences, and Endogenous Persistence," Journal of Monetary Economics, vol. 45, 657-680.

Bernanke, Ben S., and Ilian Mihov (1998): "The Liquidity Effect and Long Run Neutrality" Carnegie Rochester Series on Public Policy, vol. 49, 149-194.

Bernanke, Ben S., and Michael Woodford (1997): "Inflation Forecasts and Monetary Policy," Journal of Money Credit and Banking, vol. 24, 653-684.

Blanchard, Olivier (1997): "Comment on The New Neoclassical Synthesis and the Role of Monetary Policy," NBER Macroeconomics Annual 1997, 289-293.

Blanchard, Olivier and Kahn (1980): "The Solution of Linear Difference Models under Rational Expectations," Econometrica, vol. 48, no. 5.

Blanchard, Olivier J., and Nobuhiro Kiyotaki (1987): "Monopolistic Competition and the Effects of Aggregate Demand," American Economic Review 77, 647-666.

Blinder, Alan S., (1998): Central Banking in Theory and Practice, MIT Press.

Bullard, James and Kaushik Mitra (1999): "Learning about Monetary Policy Rules," Journal of Monetary Economics, forthcoming.

Calvo, Guillermo (1983): "Staggered Prices in a Utility Maximizing Framework," Journal of Monetary Economics, 12, 383-398.

Chari, V.V., Patrick J. Kehoe, Ellen R. McGrattan (1996): "Sticky Price Models of the Business Cycle: Can the Contract Multiplier Solve the Persistence Problem?," Federal Reserve Bank of Minneapolis, Research Department Staff Report 217.

Christiano, Lawrence J., Martin Eichenbaum, and Charles L. Evans (1997): "Sticky Price and Limited Participation Models: a Comparison," European Economic Review vol. 41, no. 6., 1201-1249.

Christiano, Lawrence J., Martin Eichenbaum, and Charles L. Evans (1999): "Monetary Policy Shocks: What Have We Learned and to What End ?," in Taylor and Woodford (eds.), Handbook of Macroeconomics, volume 1A, 65-148.

Christiano, Lawrence J., Martin Eichenbaum, and Charles L. Evans (1998): "Modeling Money," NBER WP\# 6371.

Clarida, Richard, Jordi Galí, and Mark Gertler (1998): "Monetary Policy Rules in Practice: Some International Evidence" European Economic Review, vol. 42, 10331067.

Clarida, Richard, Jordi Galí, and Mark Gertler (1999): "The Science of Monetary 
Policy: A New Keynesian Perspective," Journal of Economic Literature, vol. 37, no. 4, 1661-1707.

Clarida, Richard, Jordi Galí, and Mark Gertler (2000): "Monetary Policy Rules and Macroeconomic Stability: Evidence and Some Theory," Quarterly Journal of Economics, vol. CXV, issue 1, 147-180.

Cooley, Thomas F. and Gary D. Hansen (1989): "Inflation Tax in a Real Business Cycle Model," American Economic Review 79, 733-748.

Correia, Isabel, and Pedro Teles (1999): "The Optimal Inflation Tax," Review of Economic Dynamics, vol. 2, no.2 325-346.

Dotsey, Michael (1999): "Structure from Shocks," unpublished manuscript.

Dotsey, Michael, Robert G. King, and Alexander L. Wolman (1999): "State Dependent Pricing and the General Equilibrium Dynamics of Money and Output," Quarterly Journal of Economics, vol. CXIV, issue 2, 655-690.

Erceg, Christopher J. (1997): "Nominal Wage Rigidities and the Propagation of Monetary Disturbances," Federal Reserve Board, mimeo.

Erceg, Christopher J., Dale W. Henderson, and Andrew T. Levin (1999): "Optimal Monetary Policy with Staggered Wage and Price Contracts," Journal of Monetary Economics, forthcoming.

Fuhrer, Jeffrey C., 1997b, "The (Un)Importance of Forward_Looking behavior in Price Setting," Journal fo Money, Credit and Banking 29, August, pp. 338-50.

Fuhrer, Jeffrey C., and George R. Moore, 1995a, "Inflation Persistence", Quarterly Journal of Economics, No. 440, February, pp 127-159.

Galí, Jordi (1999): "Technology, Employment, and the Business Cycle: Do Technology Shocks Explain Aggregate Fluctuations?," American Economic Review, vol. 89, no. 1, 249-271.

Galí, Jordi and Mark Gertler (1999): "Inflation Dynamics: A Structural Econometric Analysis," Journal of Monetary Economics, vol. 44, no. 2, 195-222.

Galí, Jordi, Mark Gertler, and David López-Salido (2001): "European Inflation Dynamics," European Economic Review 45, 7, 1237-1270.

Galí, Jordi, David López-Salido and Javier Vallés (2000): "Technology Shocks and Monetary Policy: Assessing the Fed's Performance," mimeo.

Galí, Jordi (2000a): "The Conduct of Monetary Policy in the Face of Technological Change: Theory and Postwar U.S. Evidence," mimeo.

Galí, Jordi (2000b): "Targeting Inflation in an Economy with Staggered Price Setting," forthcoming in N. Loayza and R. Soto eds. Inflation Targeting: Design, Performance, Challenges, Central Bank of Chile, Santiago, Chile.

Goodfriend, Marvin, and Robert G. King (1997): "The New Neoclassical Synthesis and the Role of Monetary Policy," NBER Macroeconomics Annual 1997, 231-283.

Hairault, Jean-Olivier, and Franck Portier (1993): "Money, New Keynesian Macroeconomics, and the Business Cycle," European Economic Review 37, 33-68.

Huang, Kevin X. D., and Zheng Liu. (1998): "Staggered Contracts and Business Cycle Persistence," mimeo. 
Ireland, Peter N. (2000): "Interest Rates, Inflation, and Federal Reserve Policy since 1980," Journal of Money, Credit, and Banking, forthcoming.

Jeanne, Olivier (1998): "Generating Real Persistent Effects of Monetary Shocks: How Much Nominal Rigidity Do We Really Need?," European Economic Review, vol. 42, no. 6, 1009-1032.

Jensen, Henrik (1999): "Targeting Nominal Income Growth or Inflation," CEPR DP\# 2341.

Judd, John P., and Glenn Rudebusch (1998): "Taylor's Rule and the Fed: 19701997," Economic Review, Federal Reserve Bank of San Francisco, no. 3, 3-16.

Khan, Aubhik, Robert King, and Alexander Wolman (2000): "Optimal Monetary Policy," mimeo.

Kiley, Michael (1997): "Staggered Price Setting and Real Rigidities," Federal Reserve Board, mimeo.

Kim, Jinill (2000): "Constructing and Estimating a Realistic Optimizing Model of Monetary Policy," Journal of Monetary Economics, vol. 45, 329-359.

King, Robert G., and Alexander L. Wolman (1996): "Inflation Targeting in a St. Louis Model of the 21st Century," Federal Reserve Bank of St. Louis Review, vol. 78, no. 3. (NBER WP \#5507).

Leeper, Eric M., Christopher Sims, and Tao Zha (1996): "What Does Monetary Policy Do?," Brookings Papers on Economic Activity, vol. 2, 1-78.

Levin, Andrew T., Volcker Wieland, and John Williams (1999): “" in J.B. Taylor ed., Monetary Policy Rules, University of Chicago Press.

McCallum, Bennett, and Edward Nelson (1999): " ", in J.B. Taylor ed., Monetary Policy Rules, University of Chicago Press.

Nelson, Edward (1998): "Sluggish Inflation and Optimizing Models of the Business Cycle," Journal of Monetary Economics, 42, no. 2,303-322.

Orphanides, Athanasios (1999): "The Quest for Prosperity Without Inflation," Board of Governors, mimeo.

Roberts, John M. (1997), "Is Inflation Sticky?," Journal of Monetary Economics, No. 39, pp 173-196.

Rotemberg, Julio (1996): "Prices, Output, and Hours: An Empirical Analysis Based on a Sticky Price Model," Journal of Monetary Economics 37, 505-533.

Rotemberg, Julio and Michael Woodford (1997): "An Optimization-Based Econometric Framework for the Evaluation of Monetary Policy," NBER Macroeconomics Annual 1997, 297-346.

Rotemberg, Julio and Michael Woodford (1999): "Interest Rate Rules in an Estimated Sticky Price Model," in J.B. Taylor ed., Monetary Policy Rules, University of Chicago Press.

Rotemberg, Julio and Michael Woodford (1999): "The Cyclical Behavior of Marginal Costs,"

Sbordone, Argia (1998): "Prices and Unit Labor Costs: Testing Models of Pricing Behavior," mimeo. 
Taylor, John B., (1993) "Discretion versus Policy Rules in Practice," CarnegieRochester Series on Public Policy 39, 195-214.

Taylor, John B. (1998): "An Historical Analysis of Monetary Policy Rules," in J.B. Taylor ed., Monetary Policy Rules, University of Chicago Press.

Taylor, John B. (1999): Monetary Policy Rules, University of Chicago Press and NBER.

Vestin, David (1999): "Price-Level Targeting vs. Inflation Targeting in a Forward Looking Model," IIES, mimeo.

Walsh, Carl E. (1998): Monetary Theory and Policy, MIT Press, chapters 2-4.

Woodford, Michael (1996): "Control of the Public Debt: A Requirement for Price Stability?," NBER WP\# 5684.

Woodford, Michael (1999a): "Optimal Monetary Policy Inertia," NBER WP \#7261.

Woodford, Michael (1999b): "How Should Monetary Policy be Conducted in an Era of Price Stability?: A Comment," Princeton University, mimeo.

Woodford, Michael (1999c), Interest and Prices, chapter 6, mimeo.

Woodford, Michael (2000): "Pitfalls of Forward-Looking Monetary Policy," Princeton University, mimeo.

Yun, Tack (1996): "Nominal Price Rigidity, Money Supply Endogeneity, and Business Cycles," Journal of Monetary Economics 37, 345-370. 
Table 1

Properties of Three Simple Monetary Policy Rules

\begin{tabular}{|c|c|c|c|c|c|c|c|c|c|}
\hline & \multicolumn{3}{|c|}{ Taylor Rule } & \multicolumn{3}{|c|}{ Money Growth Peg } & \multicolumn{3}{|c|}{ Interest Rate Peg } \\
\hline & supply & $\begin{array}{l}\text { shocks } \\
\text { demand }\end{array}$ & both & supply & $\begin{array}{l}\text { shocks } \\
\text { demand }\end{array}$ & both & supply & $\begin{array}{l}\text { shocks } \\
\text { demand }\end{array}$ & both \\
\hline \multicolumn{10}{|l|}{ Baseline } \\
\hline$\sigma(\pi)$ & 0.15 & 0.15 & 0.21 & 2.29 & 0.18 & 2.30 & 2.29 & 0.28 & 2.31 \\
\hline$\sigma(x)$ & 0.16 & 0.01 & 0.16 & 0.98 & 0.11 & 0.98 & 0.98 & 0.16 & 0.99 \\
\hline$\%$ Welfare Loss & 0.001 & 0.001 & 0.002 & 0.221 & 0.001 & 0.222 & 0.22 & 0.003 & 0.22 \\
\hline \multicolumn{10}{|l|}{$\sigma=\mathbf{5}$} \\
\hline$\sigma(\pi)$ & 0.23 & 0.30 & 0.38 & 0.70 & 0.30 & 0.76 & 3.42 & 0.39 & 3.44 \\
\hline$\sigma(x)$ & 0.08 & 0.007 & 0.08 & 0.08 & 0.05 & 0.10 & 0.40 & 0.06 & 0.41 \\
\hline$\%$ Welfare Loss & 0.002 & 0.003 & 0.006 & 0.020 & 0.003 & 0.023 & 0.474 & 0.006 & 0.48 \\
\hline \multicolumn{10}{|l|}{$\theta=0.5$} \\
\hline$\sigma(\pi)$ & 0.47 & 0.20 & 0.51 & 3.18 & 0.31 & 3.20 & 3.18 & 0.46 & 3.22 \\
\hline$\sigma(x)$ & 0.08 & 0.002 & 0.08 & 0.38 & 0.05 & 0.39 & 0.38 & 0.07 & 0.39 \\
\hline$\%$ Welfare Loss & 0.0016 & 0.0003 & 0.002 & 0.070 & 0.001 & 0.071 & 0.070 & 0.001 & 0.072 \\
\hline
\end{tabular}


Figure 1. Three Conventional Output Gap Measures

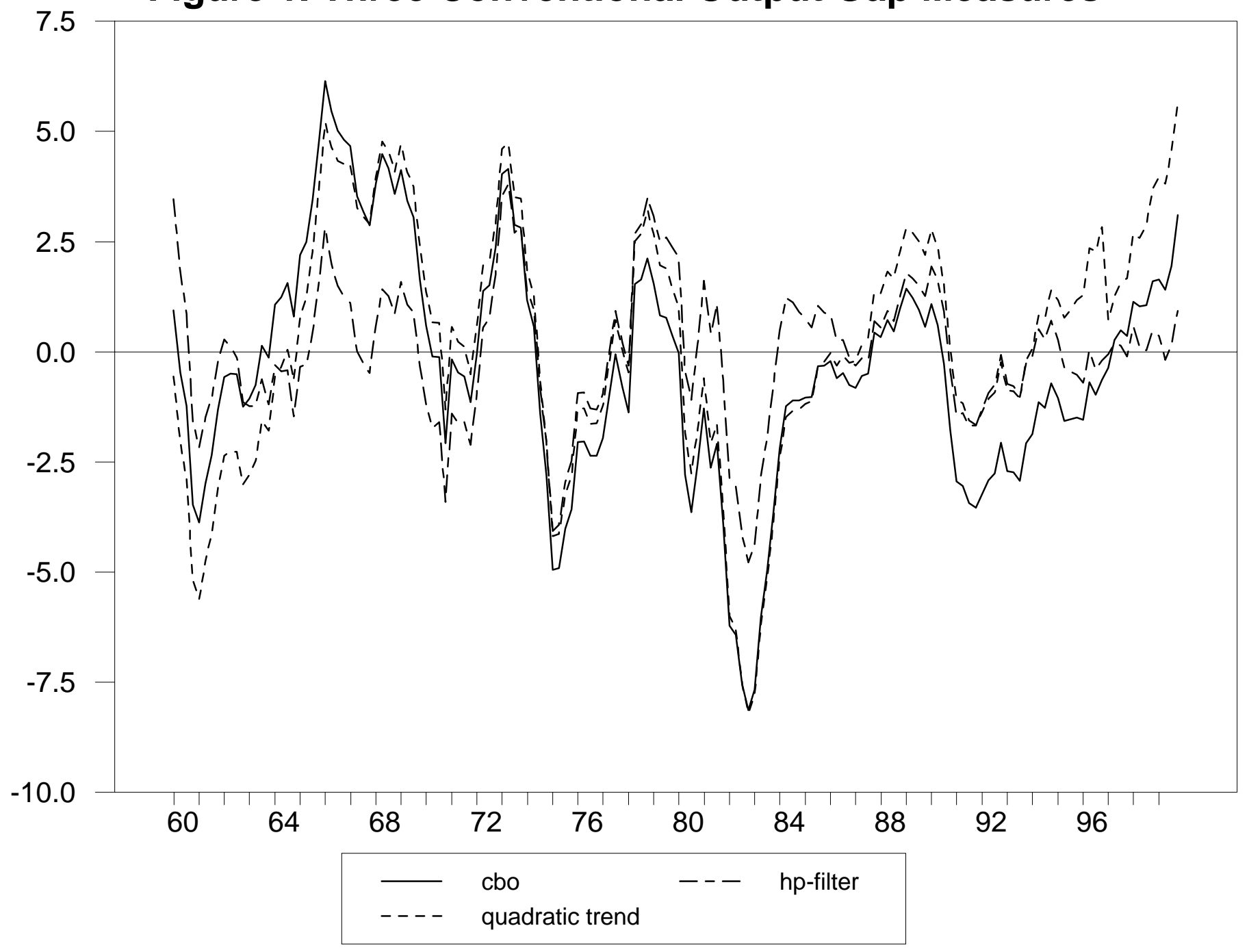


Figure 2. Model-Based Output Gap vs. Detrended GDP

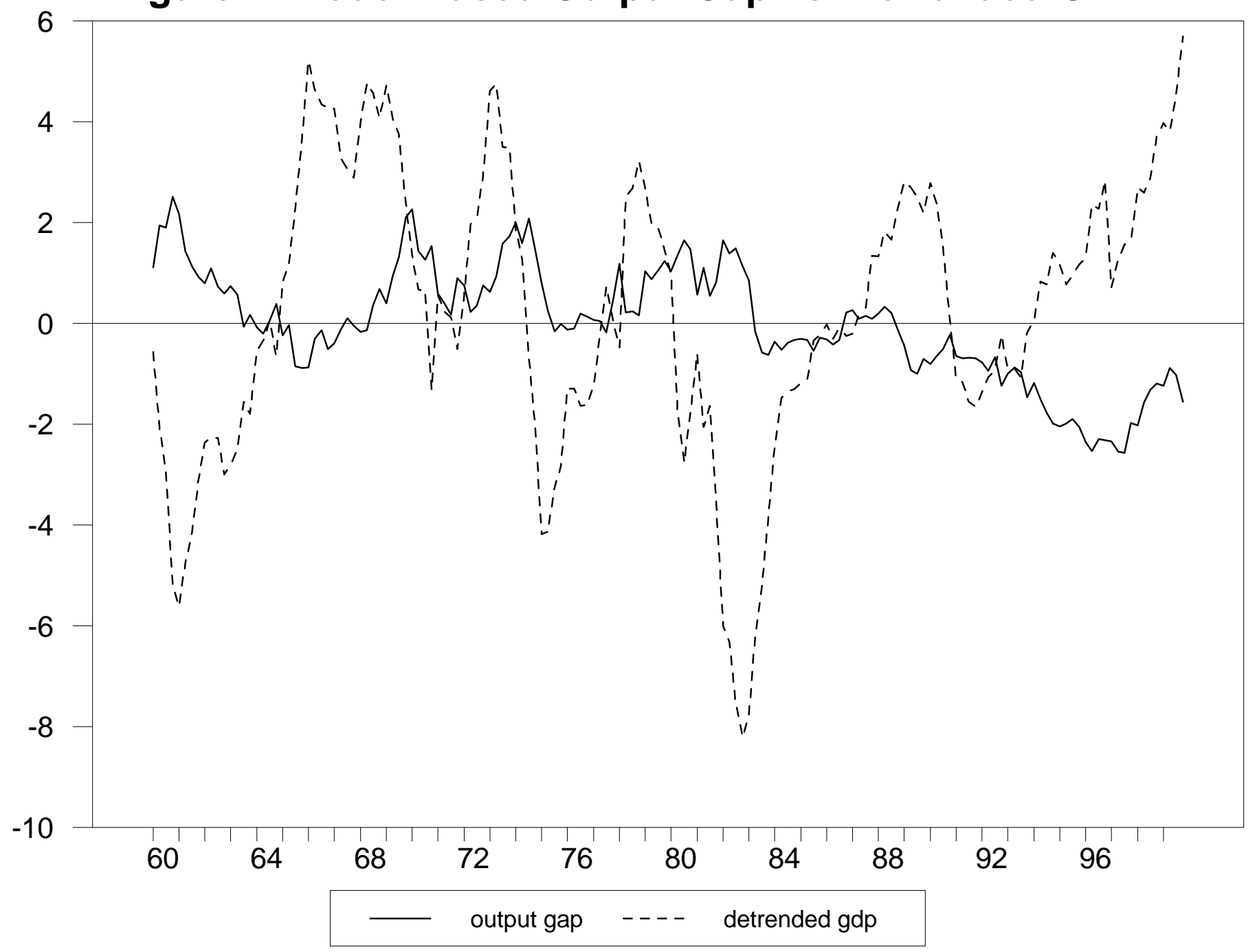


Figure 3: Dynamic Responses to a Monetary Shock
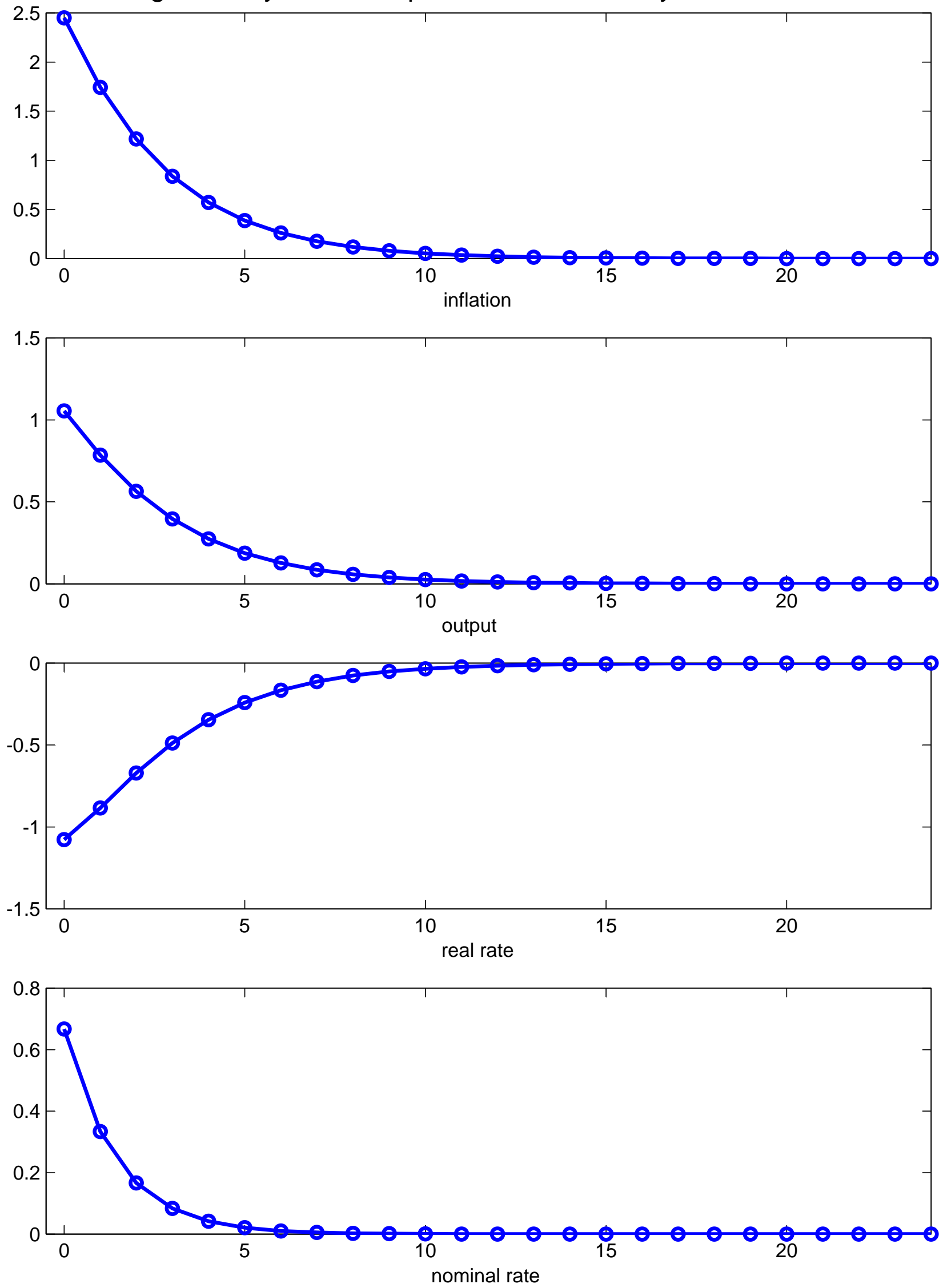
Figure 4: Monetary Shocks and the Liquidity Effect
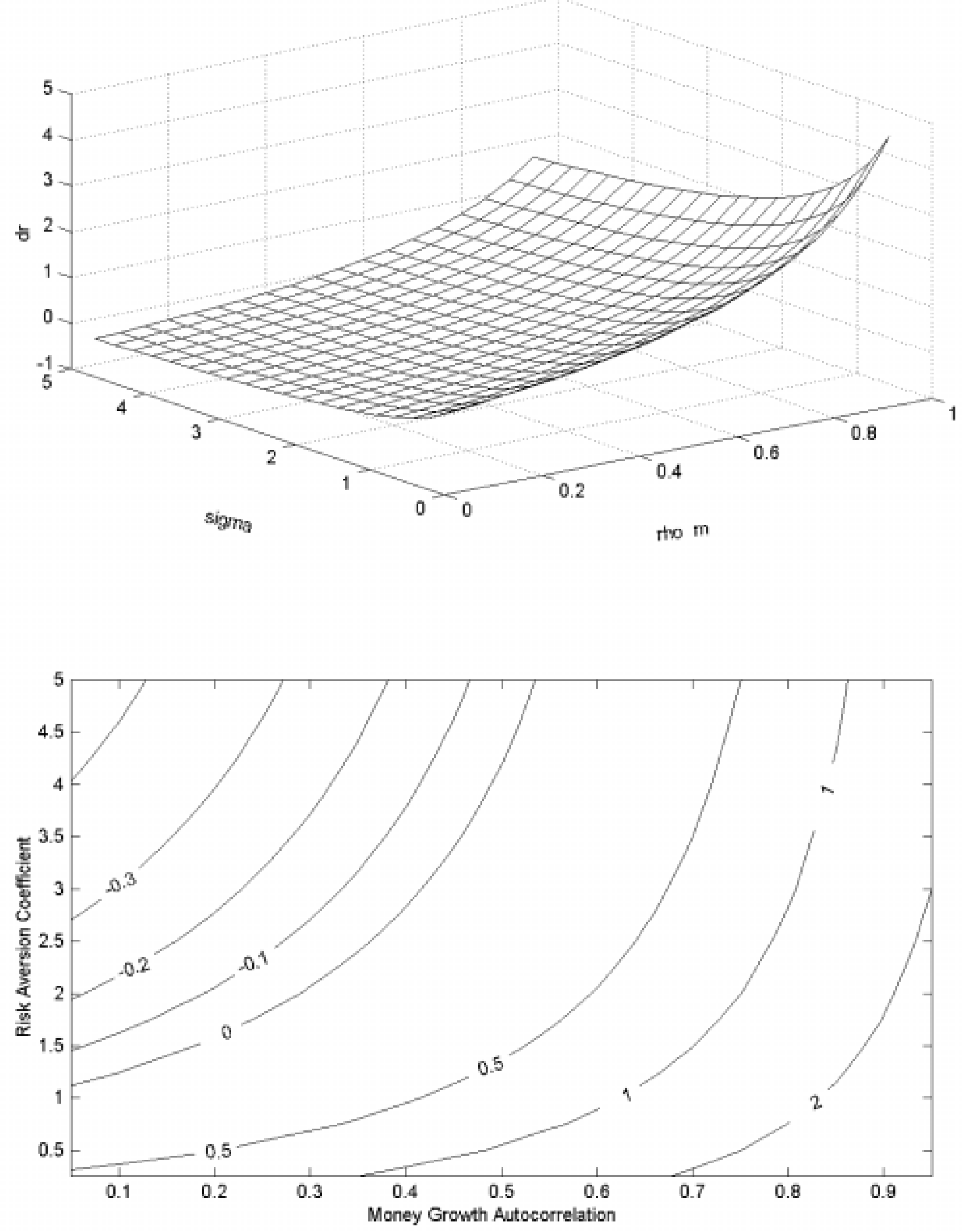
Figure 5: Dynamic Responses Responses to a Technology Shock
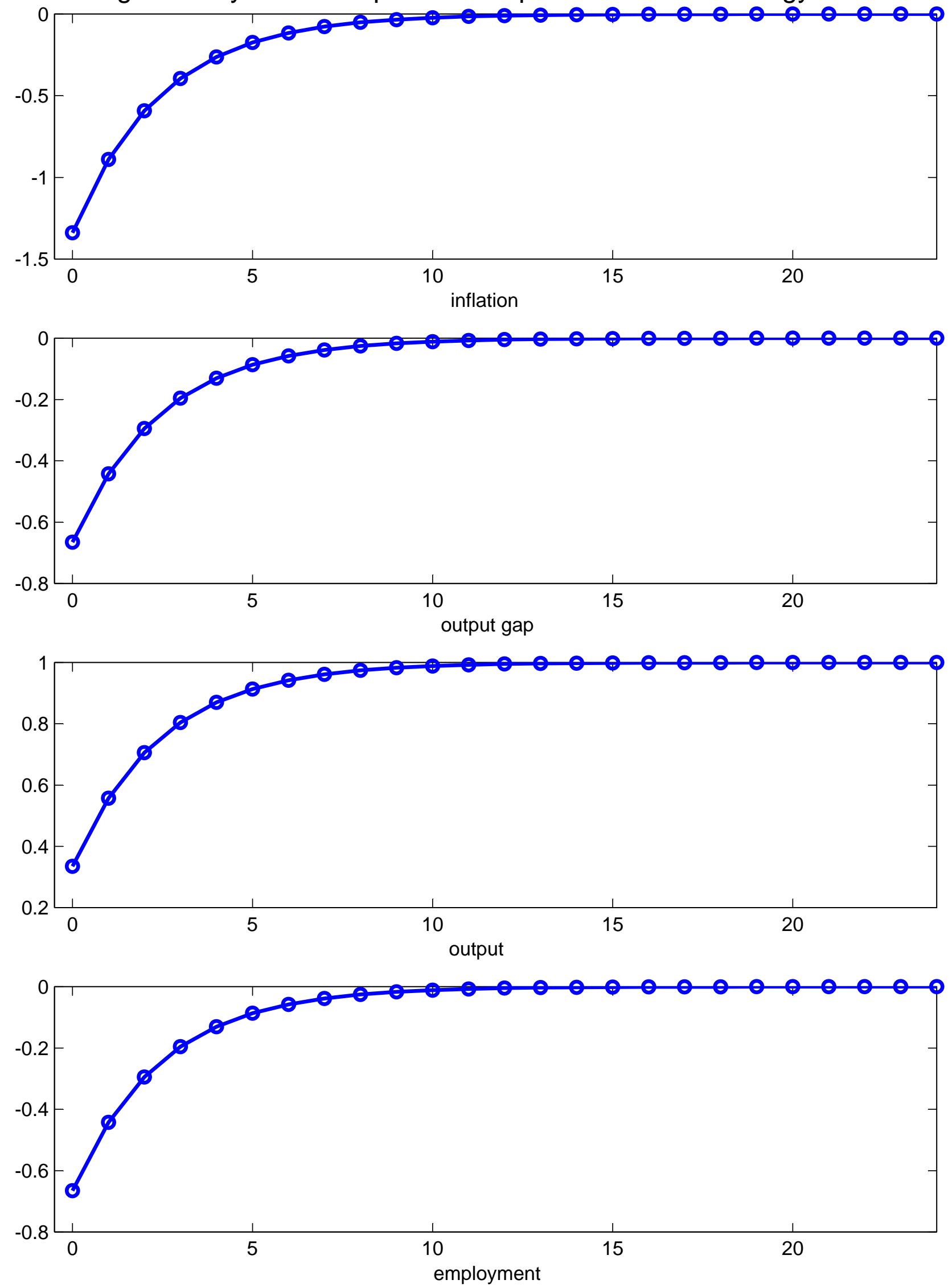
Figure 6: Technology Shocks and Employment
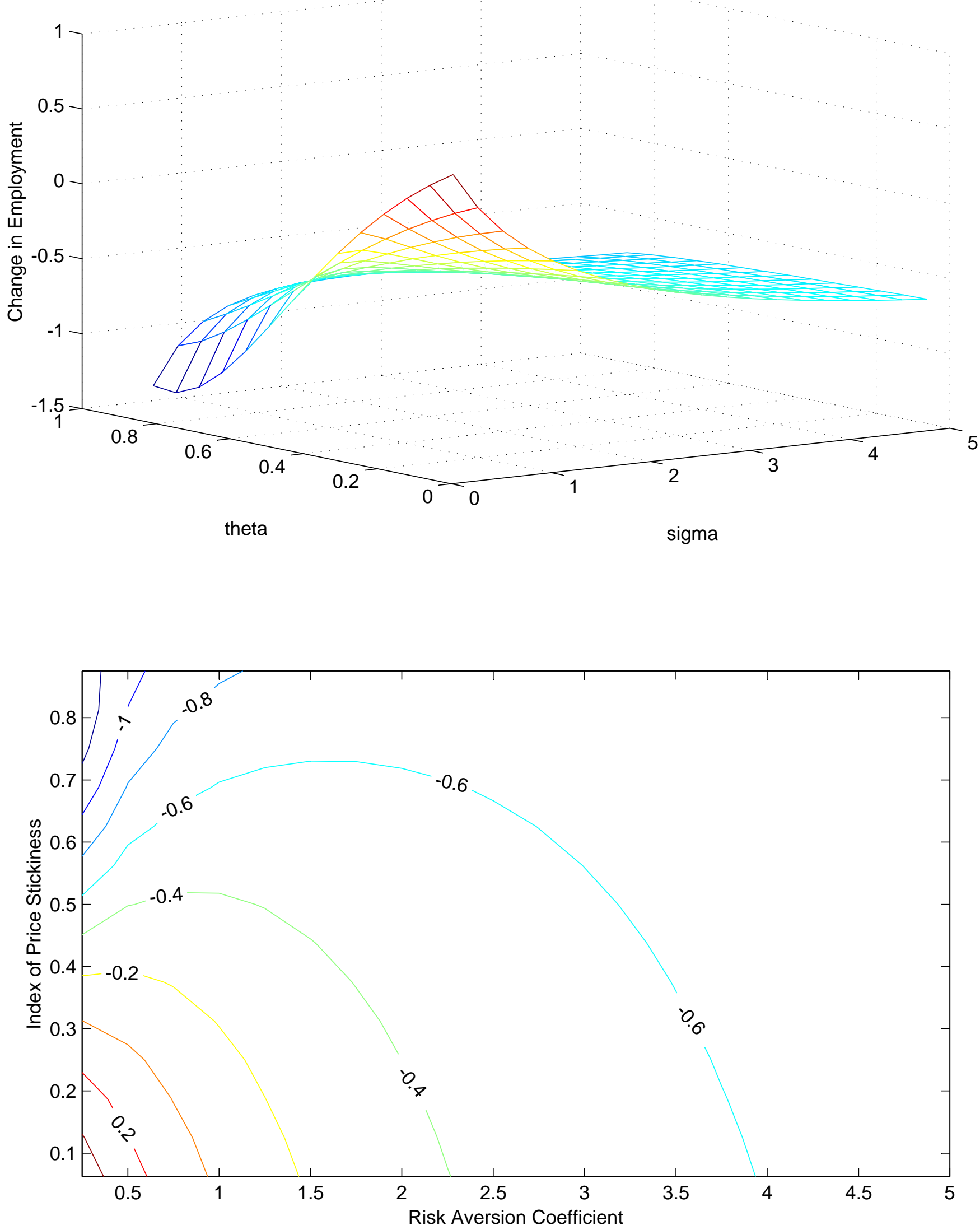
Figure 7. Commitment vs. Discretion
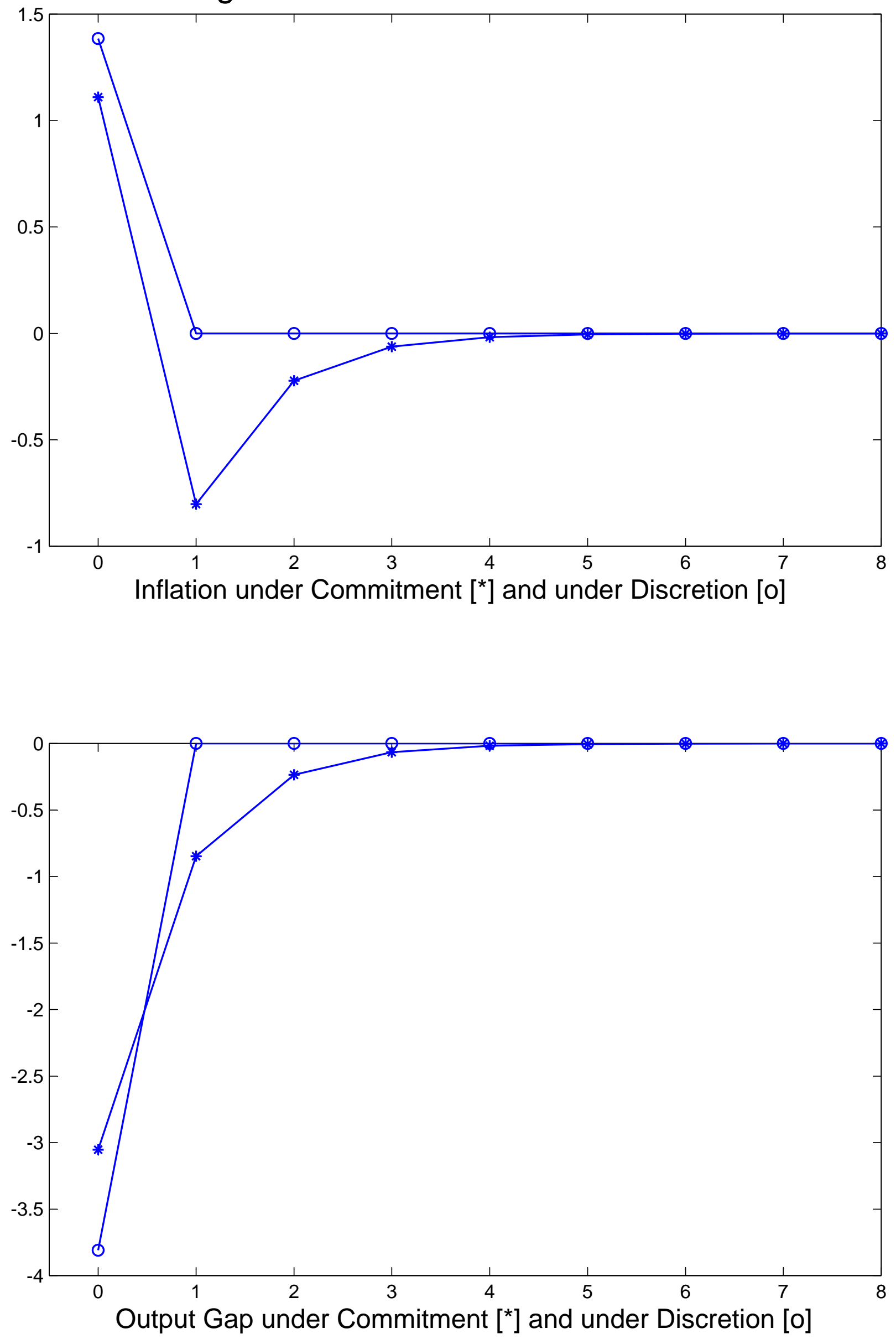